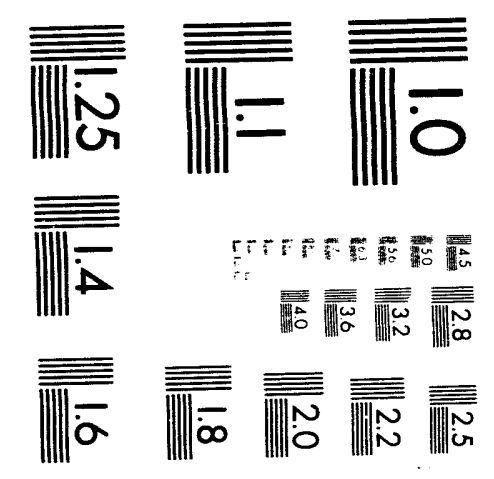



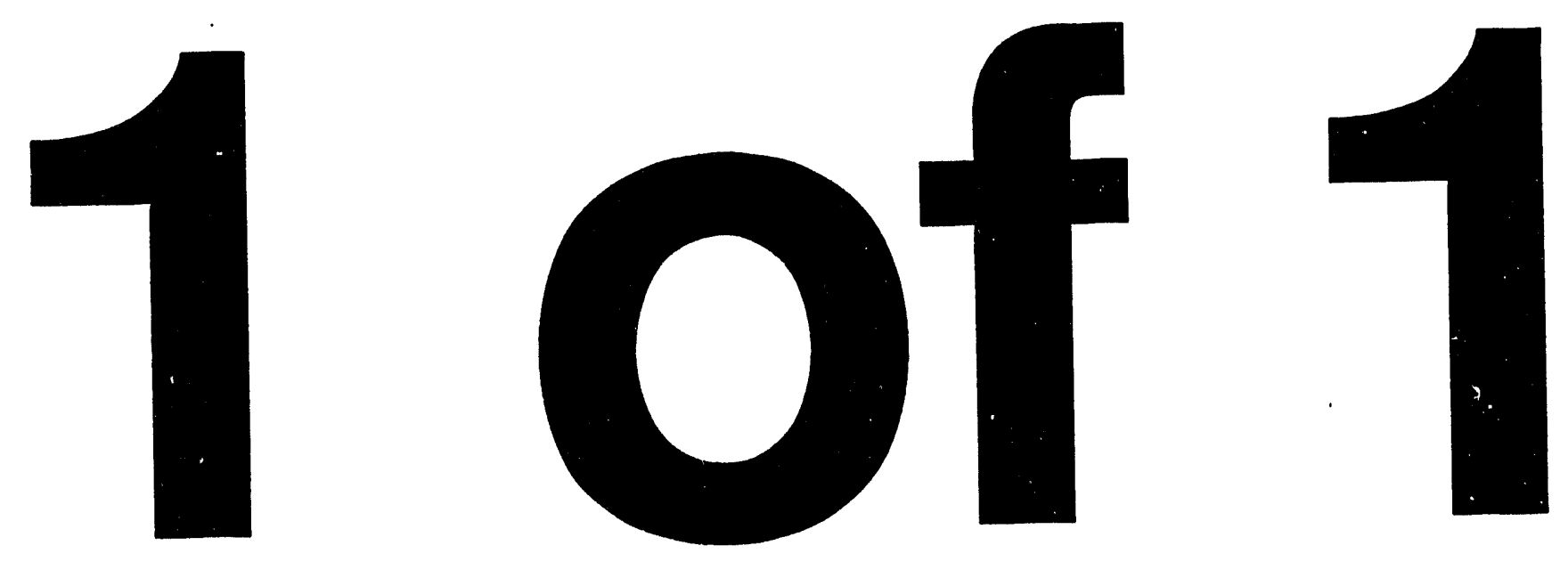
SAND93-1606C

\title{
EXPERIMENTS TO EVALUATE BEHAVIOR \\ OF CONTAINMENT PIPING BELLOWS \\ UNDER SEVERE ACCIDENT CONDITIONS
}

\author{
L. D. Lambert, M. B. Parks \\ Sandia National Laboratories \\ Albuquerque, NM 87185
}

\begin{abstract}
Bellows are an integral part of the containment pressure boundary in nuclear power plants. They are used at piping penetrations to allow relative movement between piping and the containment wall. In a severe accident they may be subjected to high pressure and temperature, and a combination of axial and lateral deflections. A test program to determine the leak-tight capacity of containment penetration bellows is being conducted at Sandia National Laboratories, Albuquerque, New Mexico. Several different bellows geometries, representative of actual containment bellows, are being subjected to extreme deflections along with pressure and temperature loads. The bellows geometries and loading conditions are described along with the testing apparatus and procedures. A total of thirteen tests have been conducted. The tests showed that bellows are capable of withstanding relatively large deformations, up to, or near, the point of full compression before developing leakage. The test data is presented and discussed.
\end{abstract}

\section{INTRODUCTION}

The bellows tests are part of the Containment Integrity Programs [1], which are being conducted at Sandia under the sponsorship of the Nuclear Regulatory Commission (NRC). The final goal of the Containment Integrity Programs is to generate a complete set of validated methods that can be used to predict containment behavior when subjected to severe accident conditions. In pursuit of this goal, a series of scale model containment buildings have been tested to failure. The models were subjected to static internal overpressurization at ambient temperatures, with the response being monitored by a large number of sensors. The measured response was then compared

\footnotetext{
${ }^{1}$ This work was supported by the U.S.Nuclear Regulatory Commission and performed at Sandia National Laboratories, which is operated by the U. S. Department of Energy under contract number DE-AC04-94AL85000.
} 
with analytical results that were compiled both before and after the test, in order to verify the analytical methods.

Because of the limited number and scale of the containment models, separate programs have been conducted to further investigate the severe accident behavior of containment penetrations. Electrical penetration assemblies, compression seals and gaskets, inflatable seals, personnel airlocks, and equipment hatches have been tested. These programs are summarized in Reference 1. The ongoing bellows experiments are a part of the containment penetration test series.

\section{BACKGROUND}

The bellows test program was initiated as a result of concerns that bellows could be a possible source of containment leakage during a severe accident. Bellows are used at the piping penetrations of steel containments to minimize the loadings imposed on the containment shell by differential movement between the pipe and the containment wall. Since these bellows are an integral part of the containment pressure boundary, they are subjected to the same conditions as the containment building. During a severe accident, those conditions would involve combinations of axial and lateral displacements, internal pressure, and elevated temperatures. Analykical methods were unable to model the bellows at the large deformations required for bellows failure [2], therefore, an experimental program was initiated. The objective of this program is to determine if bellows are a possible source of containment leakage during a severe accident, and if so, to develop methods to estimate the conditions that would likely cause such a failure.

Bellows are used primarily in steel containments, and are of two main types [3]. One type, used in both Boiling Water Reactor (BWR) and Pressurized Water Reactor (PWR) containments, is process piping bellows, which vary in size from 6 to 60 inches in diameter. The other type is vent line bellows that are used in BWR Mk-I containments. They range in size from 65 to 125 inches in diameter. Process piping bellows are normally constructed of two plies of SA240, type 304, stainless steel which are separated by a thin wire mesh ( 0.010-inch wire diameter). The redundant outer ply provides a check for leakage of the bellows by pressurizing the space between plies and noting any drop in pressure. Vent line bellows are typically one-ply; approximately $10 \%$ are two-ply. Figures 1,2 and 3 illustrate the relative location and construction details of some typical containment bellows.

Bellows are designed to accommodate differential movements that occur between the containment shell and the pipe to which they are attached. The design basis for these movements are obtained by summing the maximum deformations associated with normal operation, safe shutdown earthquake (SSE), and loss of coolant accident (LOCA). The design standards are provided by the Expansion Joint Manufacturers Association (EJMA) [4]. Normally, bellows are conservatively designed to withstand about 5000 cycles of design-basis loading, although they typically experience only a few minimal cycles due to startup and shutdown of the reactor. Design capabilities of 
two-ply bellows to resist pressure is also very conservative, as each ply is sized to resist the full containment design pressure.

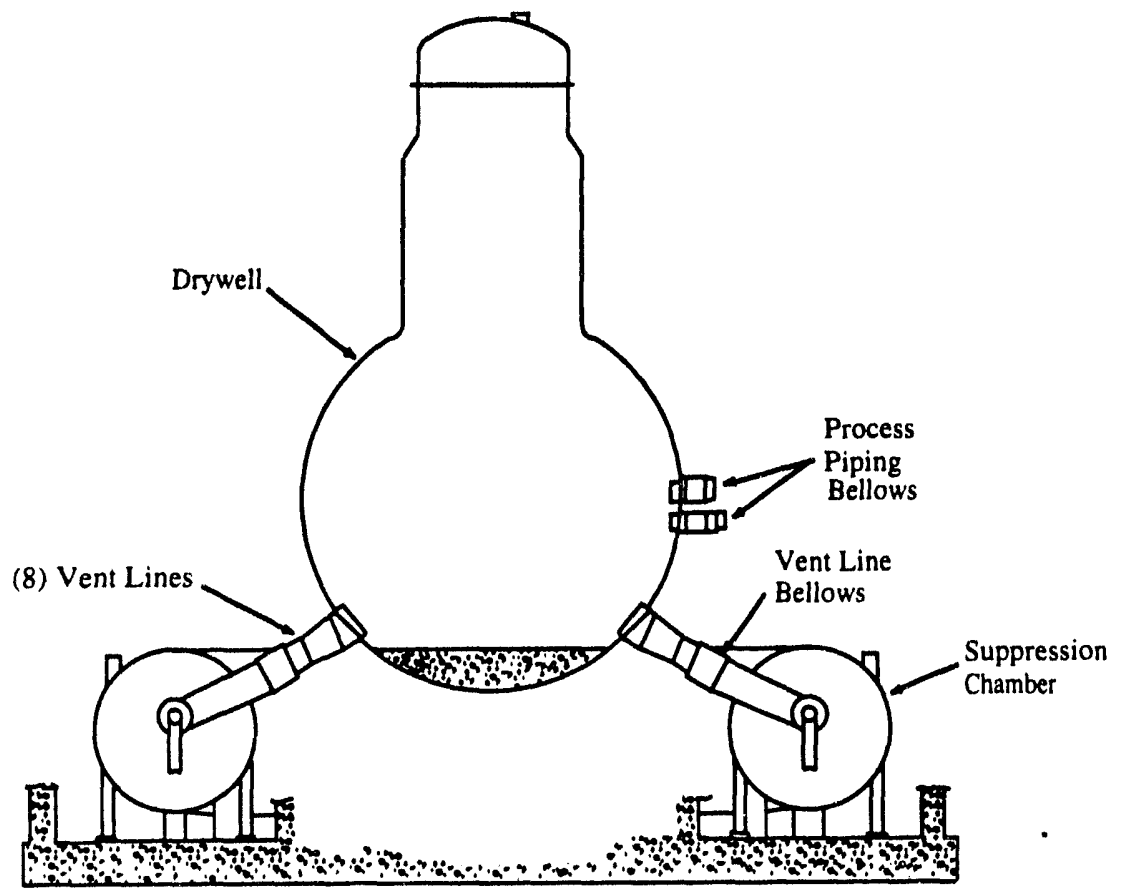

Figure 1. BWR Mark-I Containment

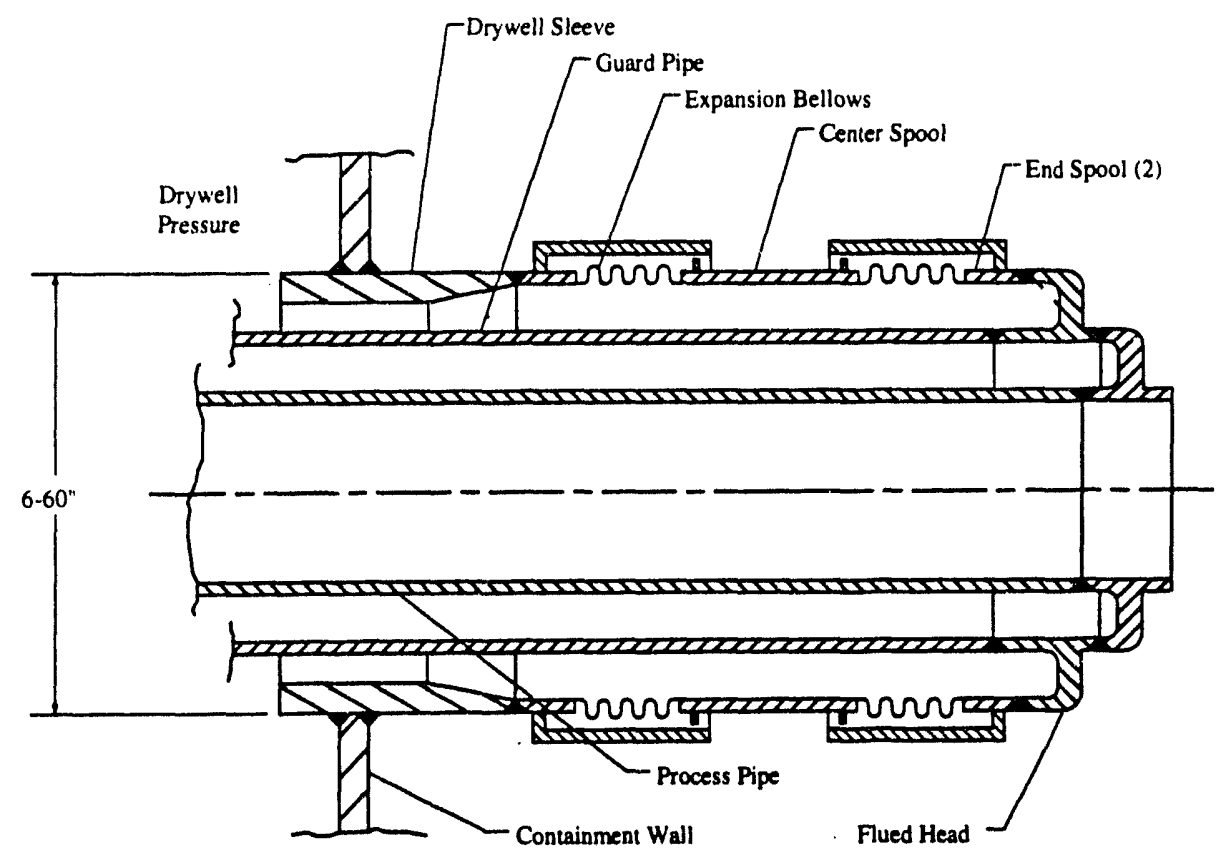

Figure 2: Typical Process Piping Bellows Configuration 


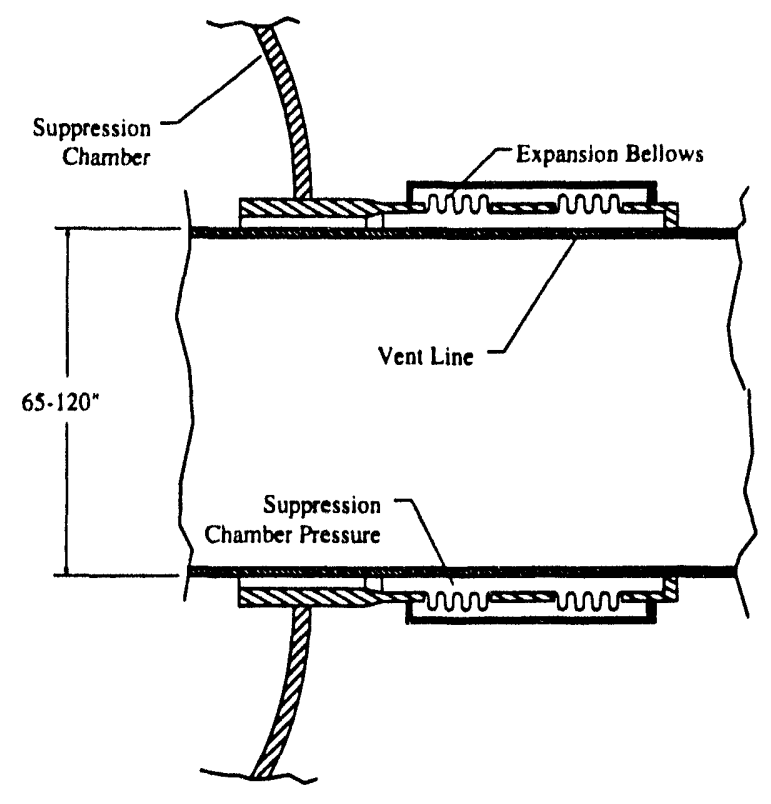

Figure 3: Typical Vent Line Bellows Configuration

In the event of a severe accident, the bellows would be subjected to pressure, temperature, and deflections well beyond the design basis. In most cases, radial growth of the containment due to internal pressure would impose axial compression on the bellows. In a few cases, the bellows would be elongated due to the bellows being installed on the inside of containment. The bellows would also be deflected transversely, due to the upward movement of the containment caused by pressure acting on the dome, and/or thermal growth of the containment shell. It is likely that the bellows would fail if the convolutions become fully compressed. Failure would occur as the end spools (see Figure 2) cut through the thin bellows material or as a result of failure of tile connection of the end spools to the piping, since these connections were not designed for transferring the movement (loading) of the containment shell directly to the piping.

After determining that no data on the performance of bellows subjected to severe accident conditions existed, a test series was formulated to examine the behavior of various bellows geometries under severe accident loadings. The test series contained thirteen tests of nine different bellows geometries that are representative of those found in actual containments.

The test series subjected representative bellows to severe accident loadings. During the tests, various levels and combinations of internal pressure, temperature, axial compression or elongation, and lateral deformation were applied. The goal of this research program is to develop methods to predict the pressure and deformation conditions that would likely cause a tear in the bellows, which would produce a leak path through the containment boundary. 
Because of the insignificant number and magnitude of loading cycles during normal operating conditions, it was decided to test the bellows in like-new condition without considering fatigue issues. Corrosion was also not considered in these experiments. Additional testing of bellows in a degraded condition is planned.

The material properties of type 304 stainless steel, which is used in the bellows construction, degrades with increasing temperature. The elongation (or 'ductility') at failure is reduced by about $35 \%$ from ambient to $400^{\circ} \mathrm{F}$ (see Figure 4). Since ductility is important in determining bellows tearing, some of the bellows tests were conducted at temperatures of $425^{\circ} \pm 25^{\circ} \mathrm{F}$.

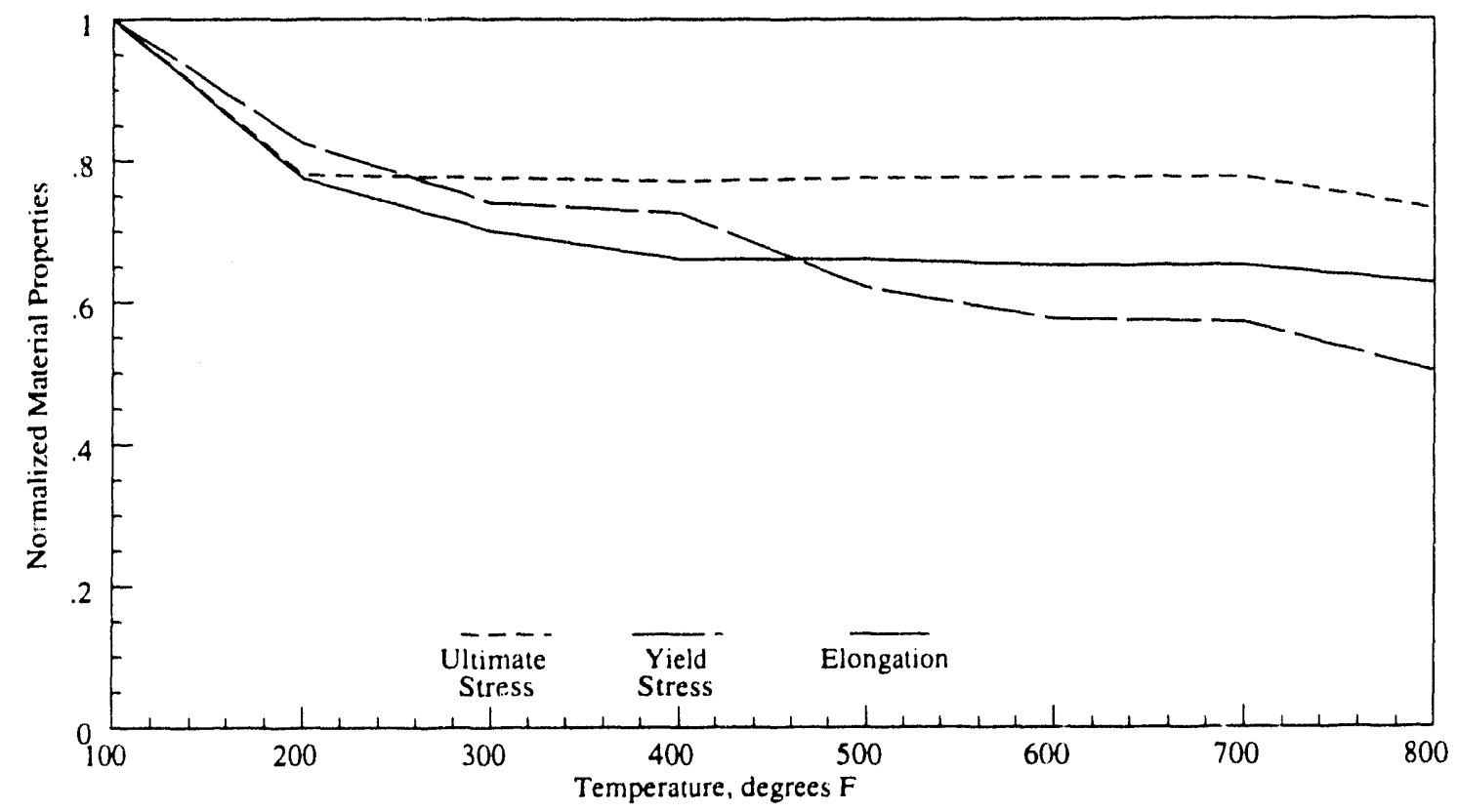

Figure 4. Effect of Elevated Temperature on Fu, Fy, and e of Type 304 Stainless Steel

\section{TEST SPECIMENS}

The specimen geometries were selected after a lengthy search to determine the types rost fiequently used by the nuclear power industry, and to derive a representative cross-section of those types. An effort to include extremes in numbers of convolutions, depth of convolutions and universal versus single element bellows (see Figure 5) was made. 


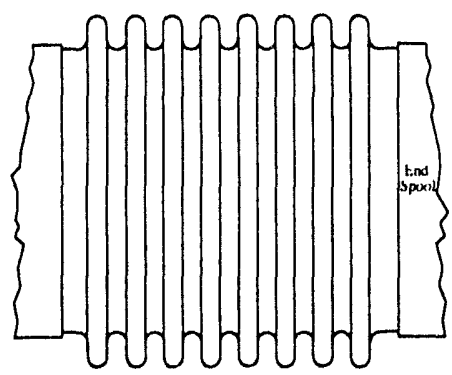

Single Element Bellows

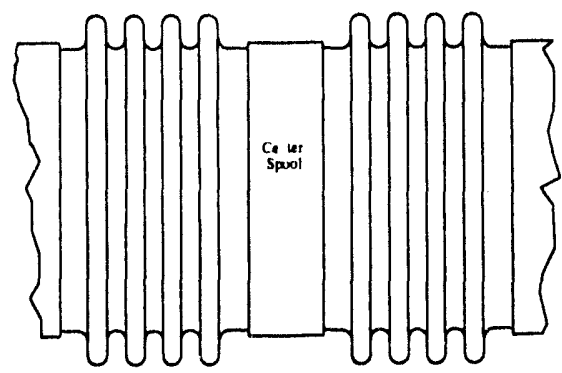

Universal Bellows

Figure 5. Bellows Configurations

The geometry of the tested bellows specimens is provided in Table 1. Figures 6 and 7 define the bellows convolution parameters listed in Table 1.

\section{DESCRIPTION OF TESTS}

The Bellows Test Series is divided into two test types. There are 11 tests of Phase I specimens and 2 tests of Phase II specimens. Phase I tests are intended to determine which, if any, of nine different geometries are more likely to leak when subjected to severe accident conditions, and to determine the capacity of bellows in general. Table 2 provides a description of the Phase I tests.

Phase II specimens are representative of specific bellows geometries, with one of the specimens representing approximately 1:4 - scale vent line bellows (VL specimens) in a BWR Mark - I and the other one being representative of a full size process piping bellows (PP specimens) in a PWR containment.

As shown in Table 1, a total of two tests were performed in Phase II. The displacements and pressures specified for this sequence are derived from analyses of the response of a containment to severe accident conditions. The first test of Phase II was of specimen PP-2. Table 2 provides a list of the combinations of internal pressure, lateral deformation and axial compression that were applied. The bellows specimens were held at $425^{\circ} \pm 25^{\circ} \mathrm{F}$ at all times during the test. As shown in Table 2, the internal pressure, axial compression, and lateral deformation were increased until the bellows was fully compressed at an internal pressure of approximately 75 psig. Per the test plan, if the bellows is still intact when fully compressed, the applied test conditions are reversed by removing axial and lateral deformation as well as internal pressure at the same rate at which each was originally applied. This process continues until either a crack develops or until all originally applied deformation and pressure has been removed. 
Table 1: Bellows Test Specimen Data

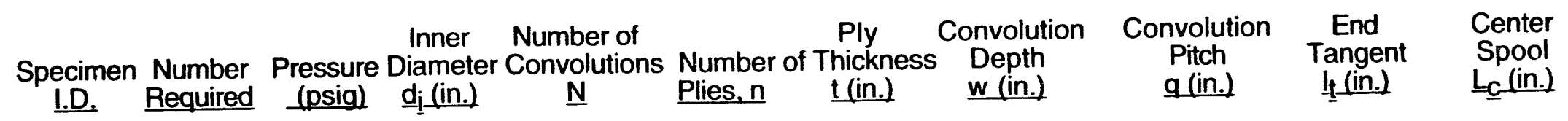

Phase 1:

$\begin{array}{llll}\text { A-8-2 } & 3 & 75 & 12.00 \\ \text { A-8-2-e } & 1 & 75 & 12.00 \\ \text { A-8-1-e } & 1 & 75 & 12.00 \\ \text { B-8-2 } & 2 & 45 & 12.00 \\ \text { B-8-2-e } & 1 & 45 & 12.00 \\ \text { B-8-1-e } & 1 & 45 & 12.00 \\ \text { B-12-2 } & 2 & 45 & 12.00 \\ \text { Subtotal } & 11 & & \end{array}$

Phase II:

\begin{tabular}{|c|c|c|c|c|c|c|c|c|c|}
\hline $\begin{array}{l}\text { PP-2 } \\
\text { VL-2 }\end{array}$ & $\begin{array}{l}1 \\
1\end{array}$ & $\begin{array}{l}25 \\
75\end{array}$ & $\begin{array}{l}19.25 \\
19.25\end{array}$ & $\begin{array}{l}6 \\
4\end{array}$ & $\begin{array}{l}2 \\
2\end{array}$ & $\begin{array}{l}0.031 \\
0.020\end{array}$ & $\begin{array}{l}1.50 \\
0.50\end{array}$ & $\begin{array}{l}1.00 \\
0.50\end{array}$ & $\begin{array}{l}2.00 \\
1.00\end{array}$ \\
\hline Subtotal & $\underline{2}$ & & & & & & & & \\
\hline
\end{tabular}

Specimen I.D. numbers in Phase I tests denote the bellows construction. The first letter (A or B) indicates convolution depth. The first number indicates the number of convolutions ( 8 or 12$)$, and the second number indicates one or two plies.

* Specimens A and B are single bellows. PP (process piping) and VL (vent line) are universal (2 convoluted sections with a center spool) bellows.

** "en indicates that the end tangent shall be attached to the outer diameter of the end spool for these specin rens (total 4). All other details of the connection are the same as shown in Figures 6 and 7 . The end tangents of the remaining specimens shall be attached to the inner diameter as shown in Figure 7. 
Table 2

Load Combinations for PP-2

Phase II Test

$\begin{array}{ccc}\begin{array}{c}\text { Internal } \\ \text { Pressure } \\ \text { (psig) }\end{array} & \begin{array}{c}\text { Lateral } \\ \text { Deformation } \\ \text { (in.) }\end{array} & \begin{array}{c}\text { Axial } \\ \text { Compression } \\ \text { (in.) }\end{array} \\ 0.2 & 0.24 & 0.13 \\ 0.6 & 0.73 & 0.39 \\ 1.0 & 1.21 & 0.64 \\ 5.0 & 1.34 & 0.73 \\ 10 & 1.48 & 0.85 \\ 20 & 1.71 & 1.08 \\ 30 & 1.90 & 1.26 \\ 40 & 2.14 & 1.47 \\ 45 & 2.06 & 1.59 \\ 50 & 2.22 & 1.77 \\ 52 & 2.25 & 1.89 \\ 54 & 2.28 & 2.08 \\ 56 & 2.31 & 2.35 \\ 58 & 2.33 & 2.80 \\ 60 & 2.34 & 3.61 \\ 62 & 2.37 & 4.45 \\ 64 & 2.39 & 5.37 \\ 66 & 2.40 & 6.37 \\ 68 & 2.42 & 7.43 \\ 70 & 2.44 & 8.55 \\ 72 & 2.46 & 9.85 \\ 74 & 2.48 & 11.25\end{array}$




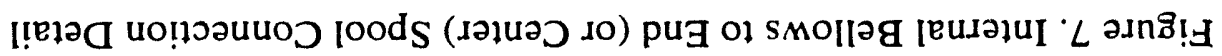

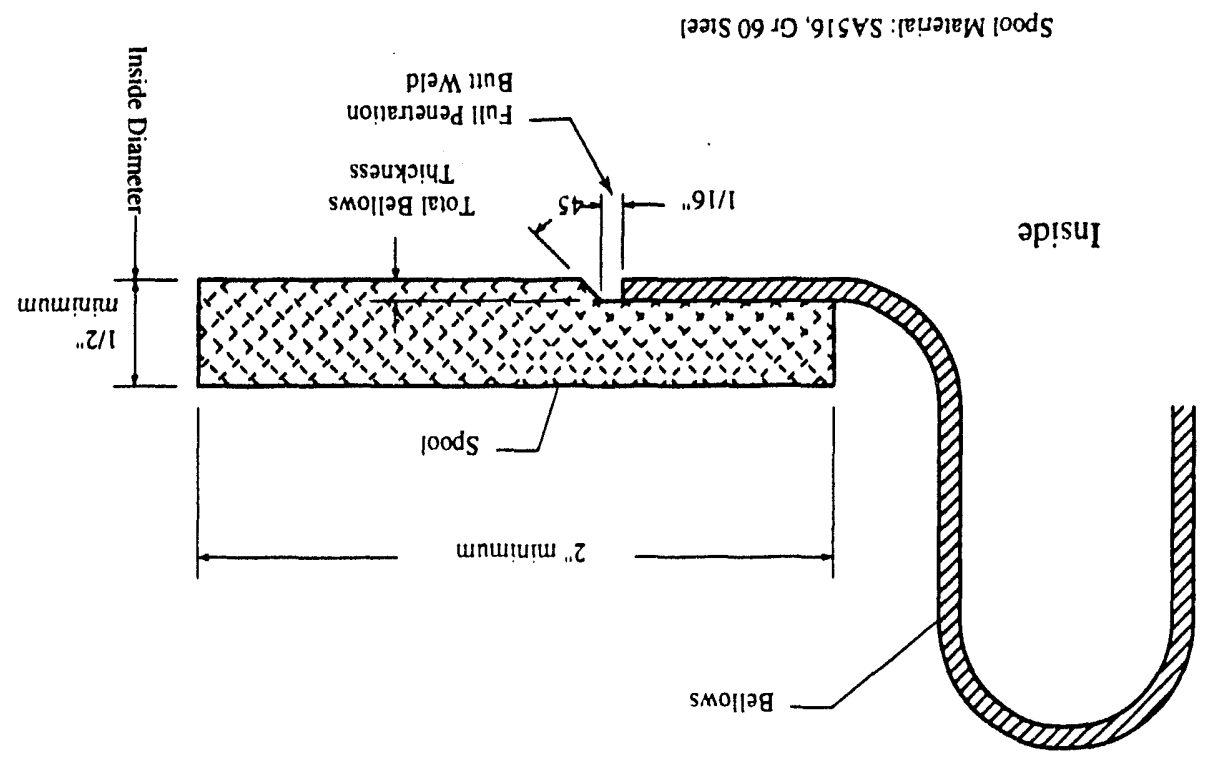

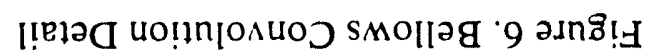

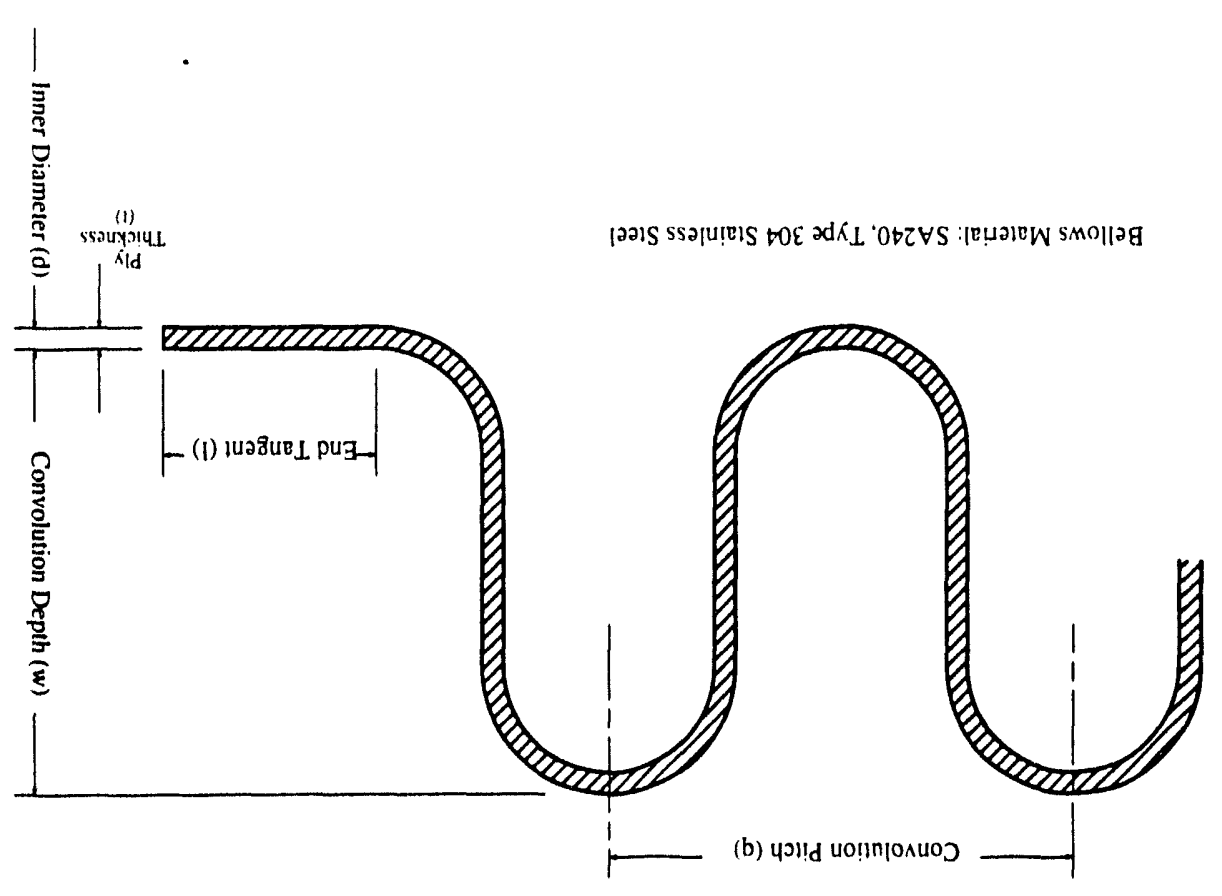


The other Phase II test was of specimen VL-2. For this test, the VL-2 specimen was simultaneously subjected to axial compression, internal pressure, and laterai deformation. These loadings were linearly increased from ambient conditions such that the internal pressure was 150 psig and the lateral deformation was 1 inch when the bellows were fully compressed axially. All points on the bellows specimen were held at $425^{\circ} \pm 25^{\circ} \mathrm{F}$ throughout the test. Per the test plan, if the bellows is still intact when fully compressed, the applied test conditions are reversed by removing axial and lateral deformation as well as internal pressure at the same rate at which each was originally applied. This process continues until either a crack develops or until all originally applied deformation and pressure has been removed.

\section{TEST APPARATUS}

All of the bellows specimens were tested on a hydraulically actuated load frame (Figure 8). The cylinders that load the bellows in the axial and lateral directions have force capabilities of 350,000 pounds and 250,000 pounds, respectively. The hydraulic power unit contains a variable flow pump for each cylinder. The flow rate is adjusted before the start of the test. The load frame is displacement-controlled by a computer that operates solenoid valves controlling the hydraulic system, based on operator commands and input from displacement transducers. That computer also controls the pressure and oil circulating system and records test data.

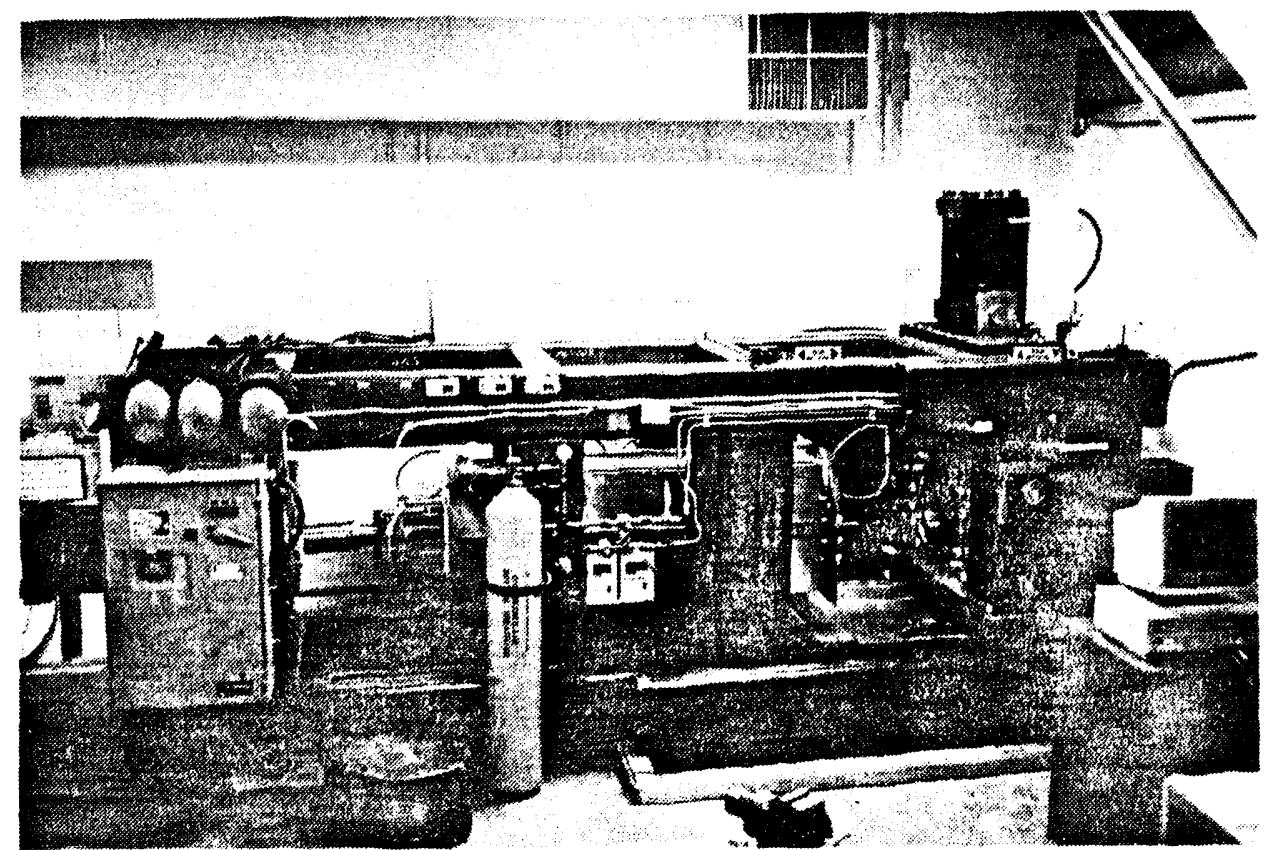

Figure 8. Bellows Load Frame 
A second computer receives load, displacement, internal pressure, and temperature data from the first and displays it in a window over a video image of the specimen during the test for recording on video tape.

A still camera also captures images of the bellows specimen during the test. A grid is superimposed over the image of the bellows by means of a partially reflective glass plate located in front of the camera, where the image of the grid is reflected.

The test specimen is bolted into the load frame by means of flanges that are welded to the end spools of the bellows. The bellows is positioned so that the axial dimension is equal to the free length of the bellows measured outside of the load frame. The bellows is then incrementally displaced as the test progresses. In the case of a test that includes internal pressure, or internal pressure and temperature, as test parameters, the bellows is filled with oil prior to being mounted in the load frame.

The pressurizing system is nitrogen gas over oil, which minimizes the stored energy in the test specimen and facilitates the input of heat to the specimen for the elevated temperature tests.

Instrumentation used during testing consists of strain gages (ambient temperature only; Figure 9), displacement transducers, load cells, thermocouples, pressure transducers, and flowmeters. Thermocouples were not used on the elevated temperature tests due to difficulties in measuring large strains at elevated temperatures.

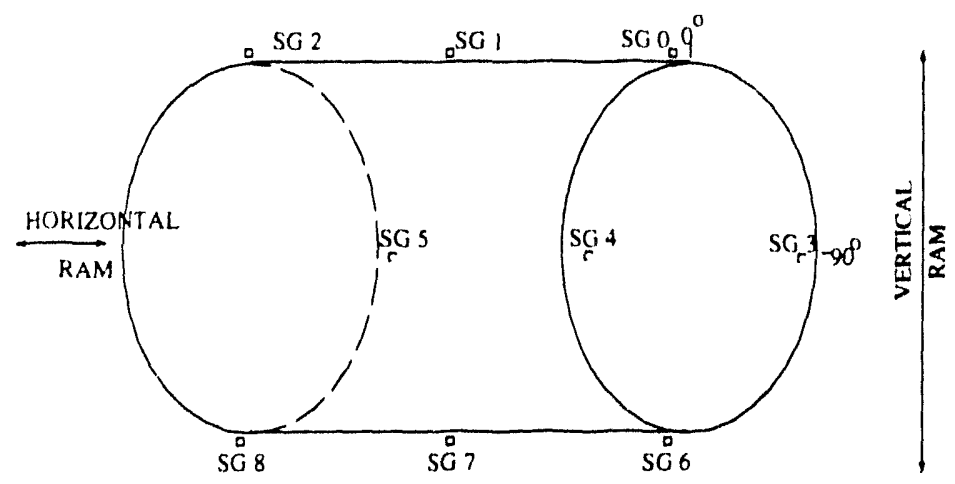

Figure 9. Strain Gage Locations

\section{SUMMARY OF TEST RESULTS}

Thitteen tests have been conducted. These tests subjected bellows to extreme axial and lateral deformations such as those that could be experienced during a severe accident. The bellows have demonstrated the ability to withstand large deformations before developing leakage. Most of the test specimens were able to endure one complete cycle of full compression, or full extension, with 2 inches of lateral displacement and remain leak tight. 
The test identification number is coded to indicate the test phase (I or II), the test number (1 through 20) and the test type (e.g. CL, SE, etc.-see Table 4).

\section{Table 3 \\ Description of Phase I Tests}

\section{Testno. Specimen 1.D. Test Designation Pressure (psig)}

Compression Tests:

$\begin{array}{cccc}2 & \text { A-8-2 } & \text { SC } & 150 \\ 3 & \text { B-8-2 } & \text { SC } & 75 \\ 4 & \text { B-3-2 } & \text { SCT } & 75 \\ 9 & \text { B-12-2 } & \text { SC } & 75 \\ 10 & \text { B-12-2 } & \text { SCT } & 75 \\ 11 & \text { A-8-2 } & \text { CL } & 0 \\ 12 & \text { A-8-2 } & \text { LC } & 0\end{array}$

Elongation Tests:

$\begin{array}{ll}13 & \text { A-8-1-e } \\ 14 & \text { A-8-2-e } \\ 15 & \text { B-8-1-e } \\ 16 & \text { B-8-2-e }\end{array}$

Test

Designation Procedure

$\mathrm{CL} \quad$ Axially compress the bellows until all convolution roots are fully compressed. If the bellows are still leak-tight, apply lateral deformation until a tear in the bellows occurs. No internal pressure will be applied during this test.

LC Apply lateral offset until the bellows become unstable (i.e., very small increase in lateral load produces relatively large lateral deformation). If the bellows are still intact, apply axial compression until all convolutions are fully compressed. If the bellows are still intact after being fully compressed, apply additional lateral deformation until a tear develops in the bellows. No internal pressure will be applied during this test.

SC Simultaneously apply internal pressure, axial compression and lateral deformation. Internal pressure, axial compression and lateral deformation shall be increased linearly such that the internal pressure pressure level in Table 2 is reached when the total applied lateral deformation is $2 "$ and the bellows are fully compressed. 


\section{Table 3 (cont.)}

If the bellows are still intact after being fully compressed, reverse the applied test conditions by removing axial and latera! deformation as well as internal pressure at the same rate at which each was originally applied. Continue unloading until either a crack develops or until all originally applied displacement and pressure has been removed.

SCT Same as SC except test temperature is $425^{\circ} \pm 25^{\circ} \mathrm{F}$ throughout the specimen for the entire test.

SE Simult neousiy apply axial elongation and lateral deformation. Axial elongation and lateral deformation shall be increased linearly such that the total applied lateral deformation is $2^{\prime \prime}$ when the bellows are fully elongated. If the bellows are still leak-tight after being fully elongated, reverse the applied test conditions by removing elongation and lateral deformation at the same rate at which each was originally applied. Continue this process until either a crack develops or until all originally applied deflection has been removed. No internal pressure will be applied during this test.

Most containment bellows are installed outside containment, where they would be subjected to internal pressure and compressive displacements in the event of a severe accident. In a few cases, however, bellows are installed inside containment, and would be subjected to external pressure and elongation during a severe accident.

Because of the relatively small number of bellows located inside containment, and the added cost and complexity of subjecting test specimens to external pressure during the tests, it was decided that external pressure would not be included in the 'SE' elongation type tests.

The test results of all the tests are summarized in Table 4.

\section{Phase I Elongation Tests}

Those tests that subjected bellows to elongation were tests $1-13$ through $1-16^{2}$ (Figure 10). In all cases, the bellows exhibited remarkable capabilities to remain leak-tight after severe deformation. Two of the four specimens $(A-8-1-\theta, A-8-2-\theta)$ remained leaktight after being displaced to their maximum extension, where all the convolutions were flattened out and the bellows was essentially a cylinder again (Figure 11). The other two specimens (B-8-1-e, B-8-2-e) were almost fully extended before developing a leak. The bellows with the deeper convolutions were more than twice their original length at full extension.

\footnotetext{
${ }^{2}$ These tests followed the SE loading condition that is described in Table 3.
} 


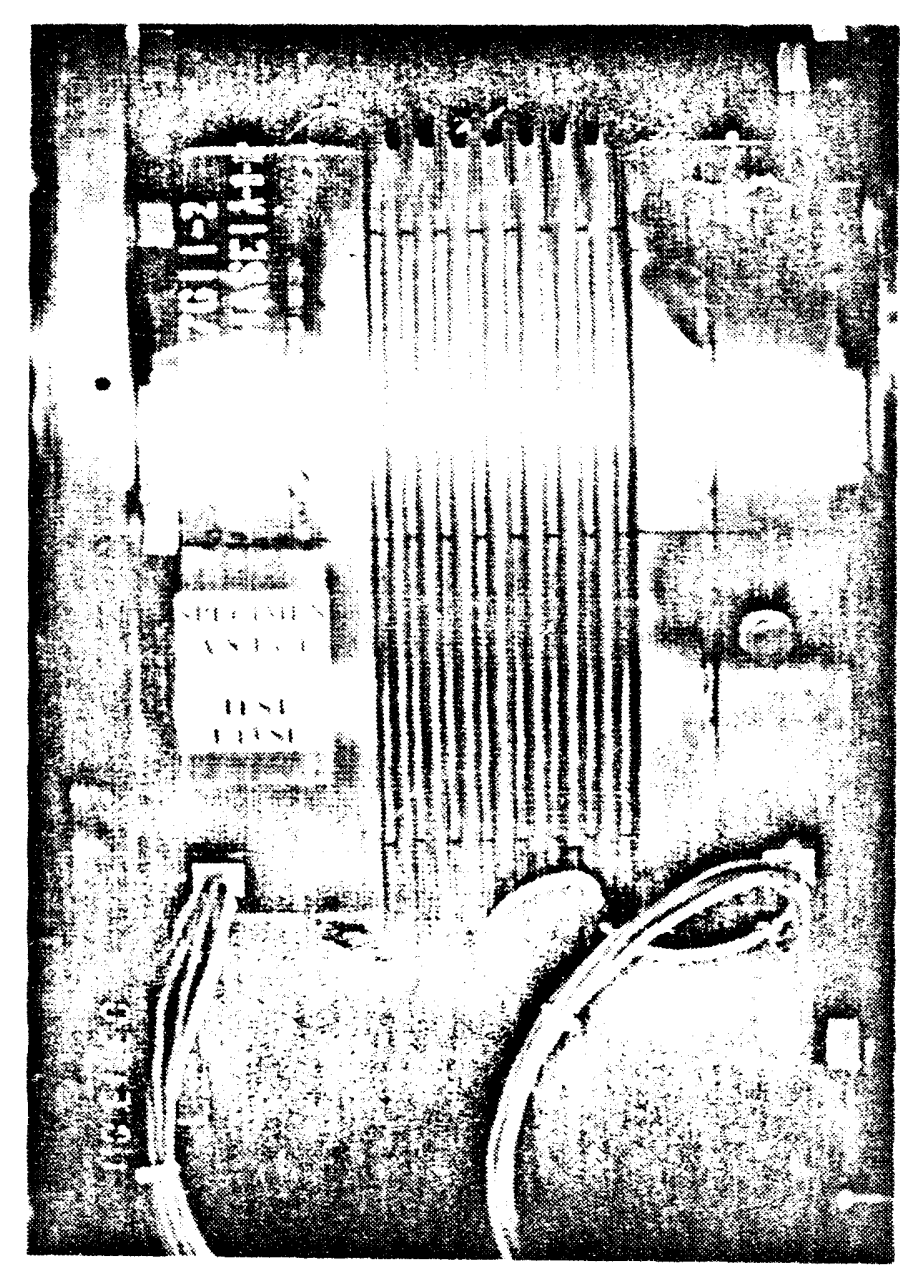

Figure 10. Bellows Specimen A-8-le-1 (Test I-13-SE)

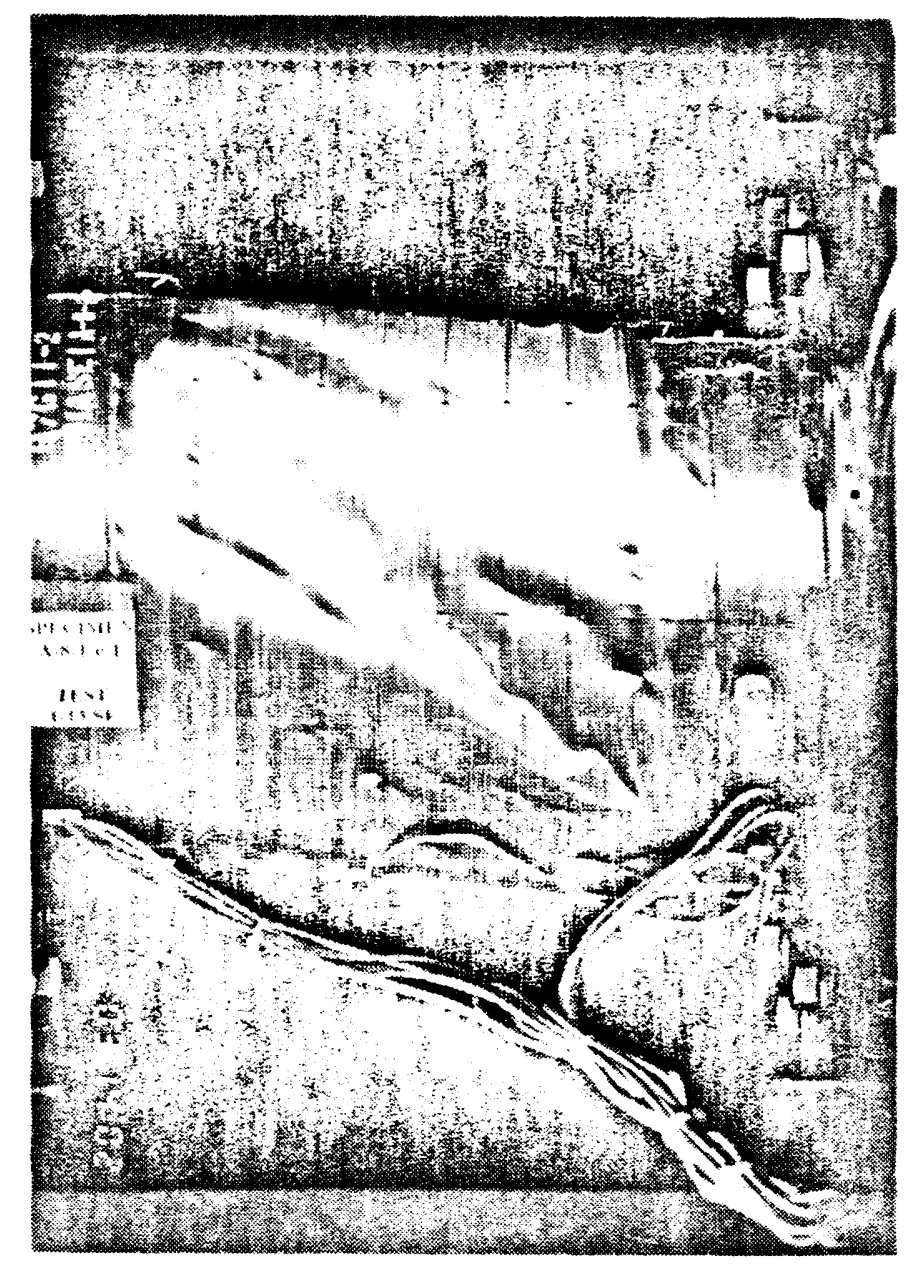

Figure 11. Bellows Specimen A-8-1e-1 At begining of Leakage (Test I-13-SE) 


\section{Table 4 \\ Bellows Failure Conditions}

\begin{tabular}{|c|c|c|c|c|c|}
\hline Test & Specimen & $\frac{\text { Pressure }}{\text { (psig) }}$ & $\frac{\text { Temperature }}{\left({ }^{\circ} \mathrm{F}\right)}$ & $\begin{array}{c}\text { Axial } \\
\text { Compression } \\
\text { (in.) }\end{array}$ & $\begin{array}{l}\text { Lateral } \\
\frac{\text { Offset }}{\text { (in.) }}\end{array}$ \\
\hline $\begin{array}{c}\text { I-11-CL } \\
\text { I-12-LC } \\
\text { |-13-SE } \\
\text { I-14-SE } \\
\text { I-15-SE } \\
\text { I-16-SE } \\
\text { I-3-SC } \\
\text { I-4-SCT } \\
\text { I-2-SCT } \\
\mid-10-S C T \\
\text { I-9-SC } \\
\text { |1-19-SCT } \\
\mid 1-17-S C T\end{array}$ & $\begin{array}{c}\text { A-8-2-1 } \\
\text { A-8-2-2 } \\
\text { A-8-1-e } \\
\text { A-8-2-e } \\
\text { B-8-1-e } \\
\text { B-8-2-e } \\
\text { B-8-2-1 } \\
\text { B-8-2-2 } \\
\text { A-8-2-3 } \\
\text { B-12-2-1 } \\
\text { B-12-2-2 } \\
\text { VL-2 } \\
\text { PP-2 }\end{array}$ & $\begin{array}{l}\text { NA } \\
\text { NA } \\
\text { NA } \\
\text { NA } \\
\text { NA } \\
\text { NA } \\
75 \\
65 \\
150 \\
68 \\
72 \\
150 \\
74\end{array}$ & $\begin{array}{l}\text { NA } \\
\text { NA } \\
\text { NA } \\
\text { NA } \\
\text { NA } \\
\text { NA } \\
\text { NA } \\
415 \\
420 \\
410 \\
\text { NA } \\
415 \\
400\end{array}$ & $\begin{array}{c}3-1 / 4^{3} \\
3-3 / 8^{3} \\
-5-3 / 4^{4} \\
-6^{4} \\
-17^{4} \\
-18^{4} \\
4-3 / 4^{3} \\
4-5 / 8 \\
3-3 / 4^{3} \\
7-3 / 8 \\
8-3 / 8 \\
3^{3} \\
10-1 / 2^{3}\end{array}$ & $\begin{array}{c}2-5 / 8 \\
2-3 / 8 \\
1-1 / 4 \\
2 \\
2 \\
2 \\
2-1 / 4 \\
1-7 / 8 \\
2 \\
1-7 / 8 \\
2 \\
2-7 / 8 \\
5\end{array}$ \\
\hline
\end{tabular}

\section{Phase I Axial Compression Tests}

A total of seven Phase I tests were conductid in which the bellows were compressed axially. Two tests were done to determine the most severe loading sequence for the bellows. In one test (1-12-LC) the specimen was subjected to a 2 inch lateral displacement followed by compressing the bellows until all the convolutions and the end spools were in metal-to-metal contact (Figure 12) ${ }^{5}$. The lateral displacement was limited to 2 inches based on conservative estimates of the amount of vertical displacement that the containment building could experience during a severe accident 6 . The other test $(1-11-C L)$ reversed the loading sequenco with the bellows being fully compressed at the start of lateral displacement (Figure 13). In both cases, the bellows remained leak-tight up to the point of full compression and further displacement in the lateral direction was required to cause a leak. In test 1-12-LC, the loading sequence was reversed and the specimen was returned to the starting point and loaded again, before being displaced laterally to approximately $2-3 / 8$ inches where a leak developed.

Five other tests examined bellows performance when subjected to additional loads in the form of elevated temperature and pressure. All of these tests were simultaneous compressive tests, with the displacement being incremented both axially and laterally at each load step.

\footnotetext{
${ }^{3}$ Reached full compression without leakage.

${ }^{4}$ Elongation shown as negative value.

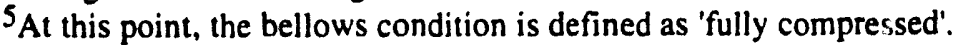

${ }^{6}$ Two inches seems to be an upper bound on the gap between the outside of the piping and the containment opening.
} 


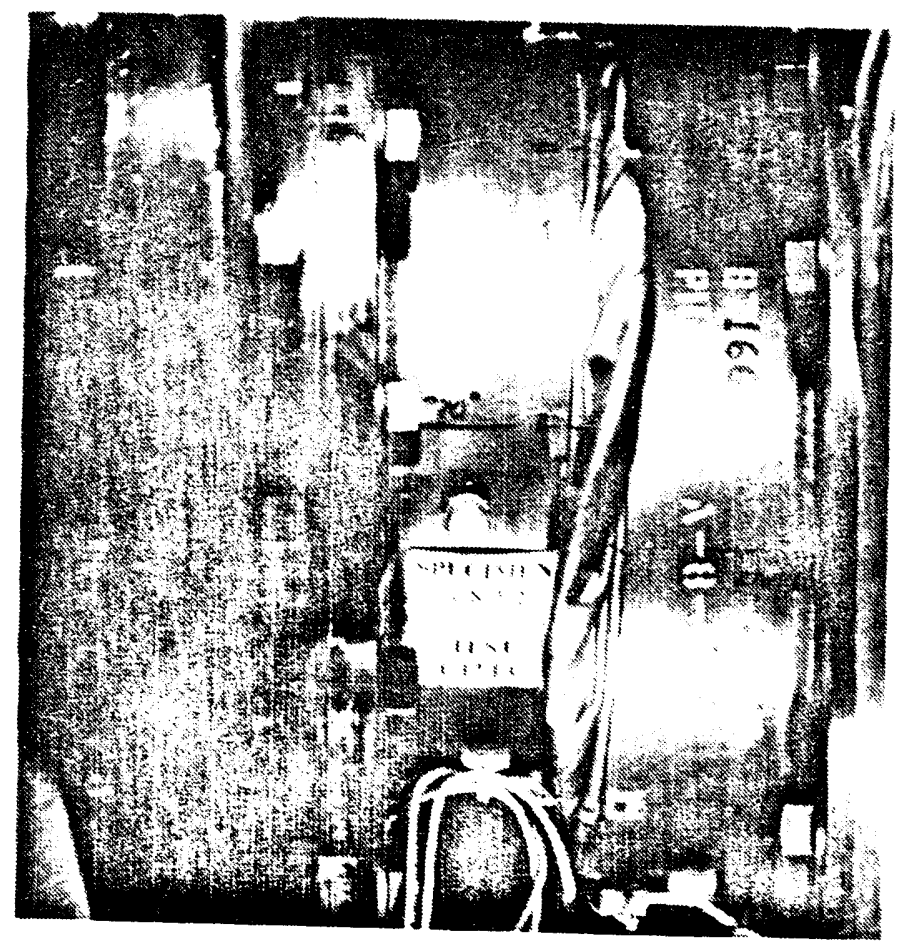

Figure 12. Bellows Specimen A-8-2-2

Fully Compressed

(Test 1-12-LC)

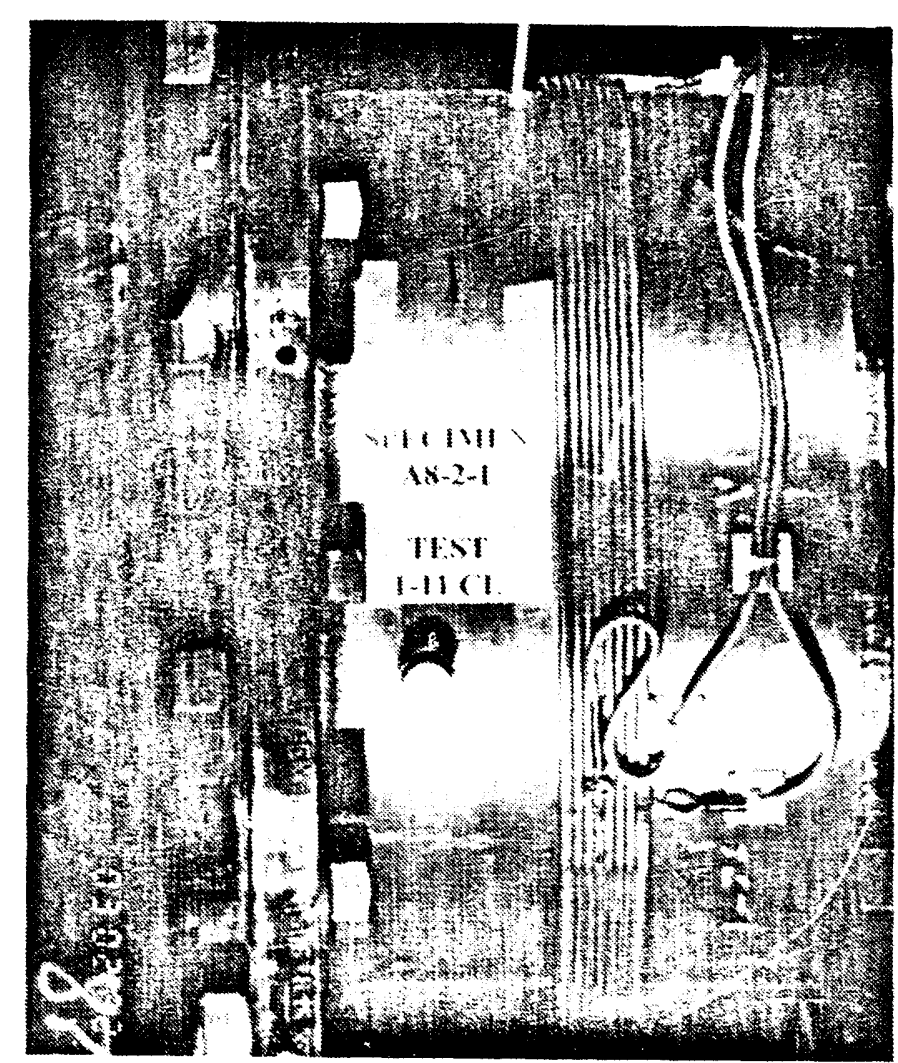

Figure 13. Bellows Specimen A-8-2-1 Fully Compressed (Test I-11-CL) 
The pressure was also incremented so that the maximum pressure was reached concurrent with maximum displacement. The temperature of the bellows was increased to $425^{\circ} \mathrm{F} \pm 25^{\circ} \mathrm{F}$ before the start of an elevated temperature test. The temperature was maintained throughout the test.

One test was completed using a bellows with 1/2 inch deep convolutions (Test 1-2SCT) and two-ply construction. The bellows temperature was $425^{\circ} \mathrm{F}$ throughout the test. The specimen was subjected to full axial compression and 2 inch lateral displacement without leaking. The internal pressure was 150 psig at the maximum displacements. Upon reversing the displacement direction so that the bellows was being extended toward its original dimensions, a leak developed through one ply. Only after being fully compressed and extended for a second time, did the bellows develop a leak through both plies.

Tests 1-3-SC and 1-4-SCT were conducted on identical specimens :vith 1-1/4 inch convolution depth. Both specimens were subjected to internal pressure, but only the specimen tested in 1-4-SCT was heated to $425^{\circ} \mathrm{F}$. Both specimens remained leak-tight during large displacements. The heated specimen failed just before reaching the fully compressed state, at axial and lateral displacements of 4-5/8 inches and 1-7/8 inches, respectively, at an internal pressure of 65 psig (full compression would have occurred at axial displacement of 5 inches), however, the room temperature bellows remained leak-tight up to the point of full axial compression. The room temperature bellows eventually failed during the reversal of displacement direction (displacements of 4-1/4 inches and 2 inches axially and laterally, respectively) after maximum axial and lateral displacements of 4-3/4 inches and $2-1 / 4$ inches, respectively (Figures 14 \& 15).

The fact that the bellows in the elevated test failed earlier than identical bellows at room temperature is consistent with the loss of ductility that occurs in the bellows material with increasing temperature, as shown in Figure 4.

The bellows constructed with deeper convolutions develop sharp creases in the crest of the convolutions relatively early in the displacement cycle compared to the bellows with shallower convolutions. Development of these sharp creases appeared to be soon followed by tears in the bellows material. Thus, the bellows with relatively shallow convolutions seem to be more resistant to extreme deformations than those with deeper convolutions. An example of the sharp creases developed in specimen B8-2-1 during Test 1-3-SC is shown in Figure 16. These sharp creases eventually tear and leak.

Two identical bellows with 12 of the deeper convolutions were examined in tests 1-9SC and 1-10-SCT. The convolutions are 1-1/4 inch deep and are very flexible (Figure 17). A relatively large axial displacement was required to close the gap between all the convolutions and the end spools. The bellows were subjected to more than 8 inches of axial compression along with 2 inches of lateral deflection. Again, the heated bellows failed slightly earlier than the room temperature specimen. 


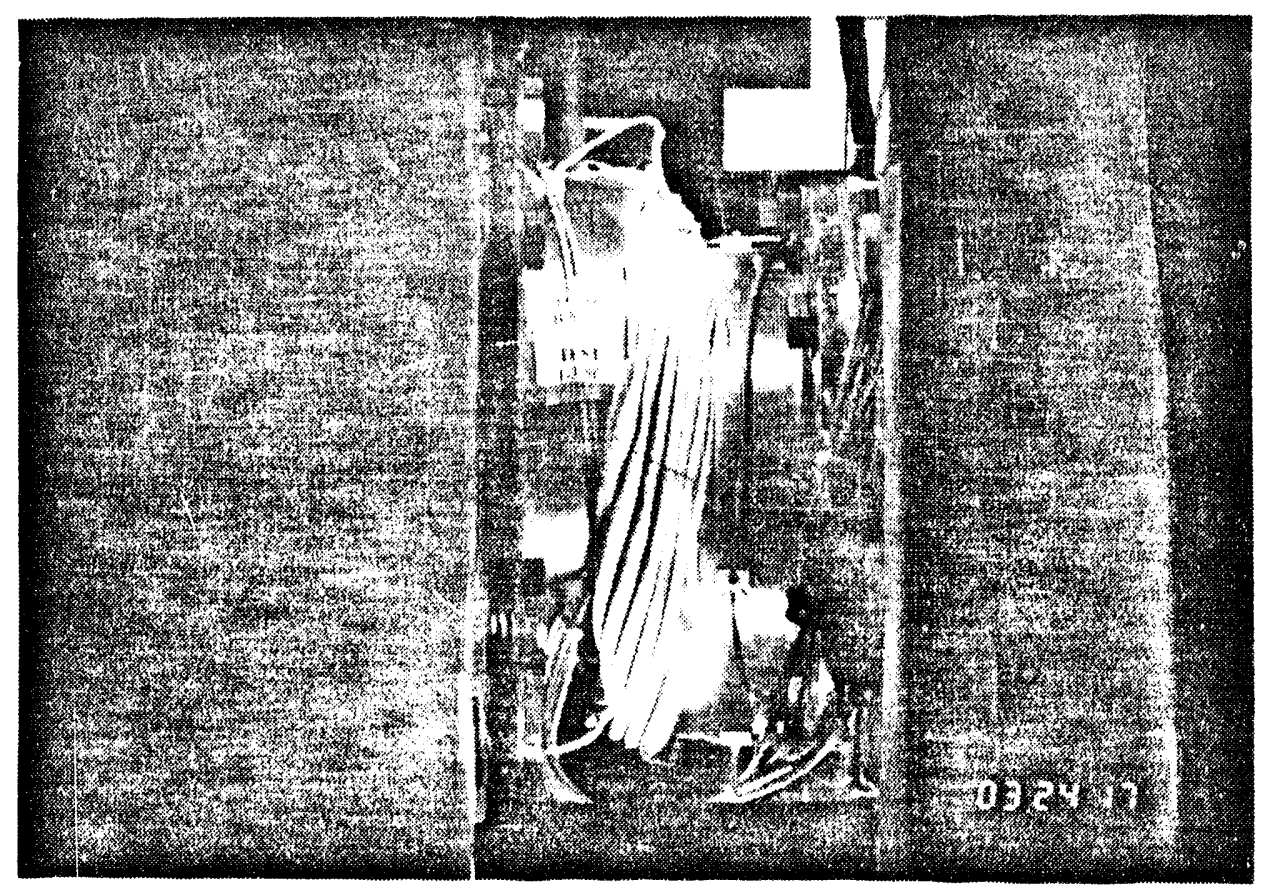

Figure 14. Bellows Specimen B-8-2-1 Fully Compressed

(Test I-3-SC)

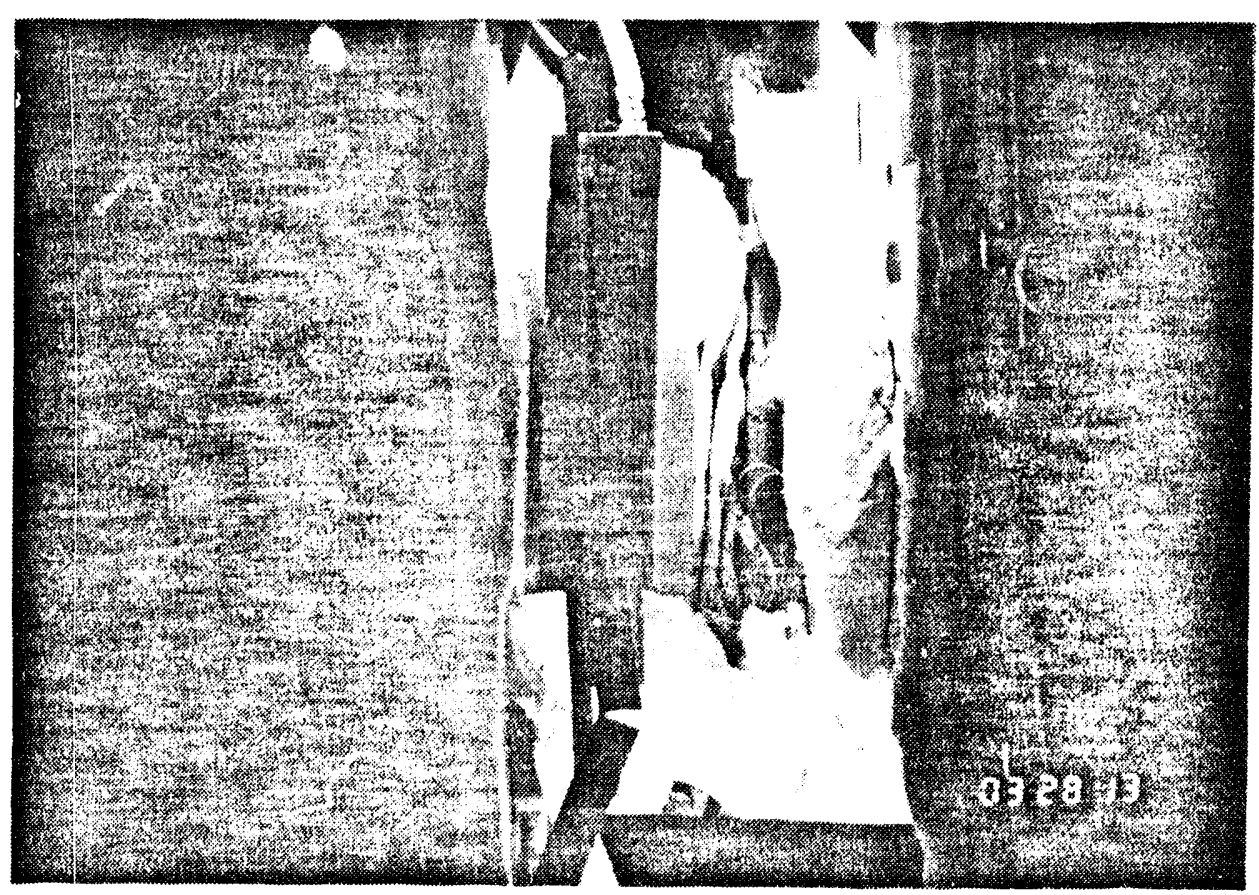

Figure 15. Bellows Specimen B-8-2-2 Fully Compressed

(Test I-4-SCT) 


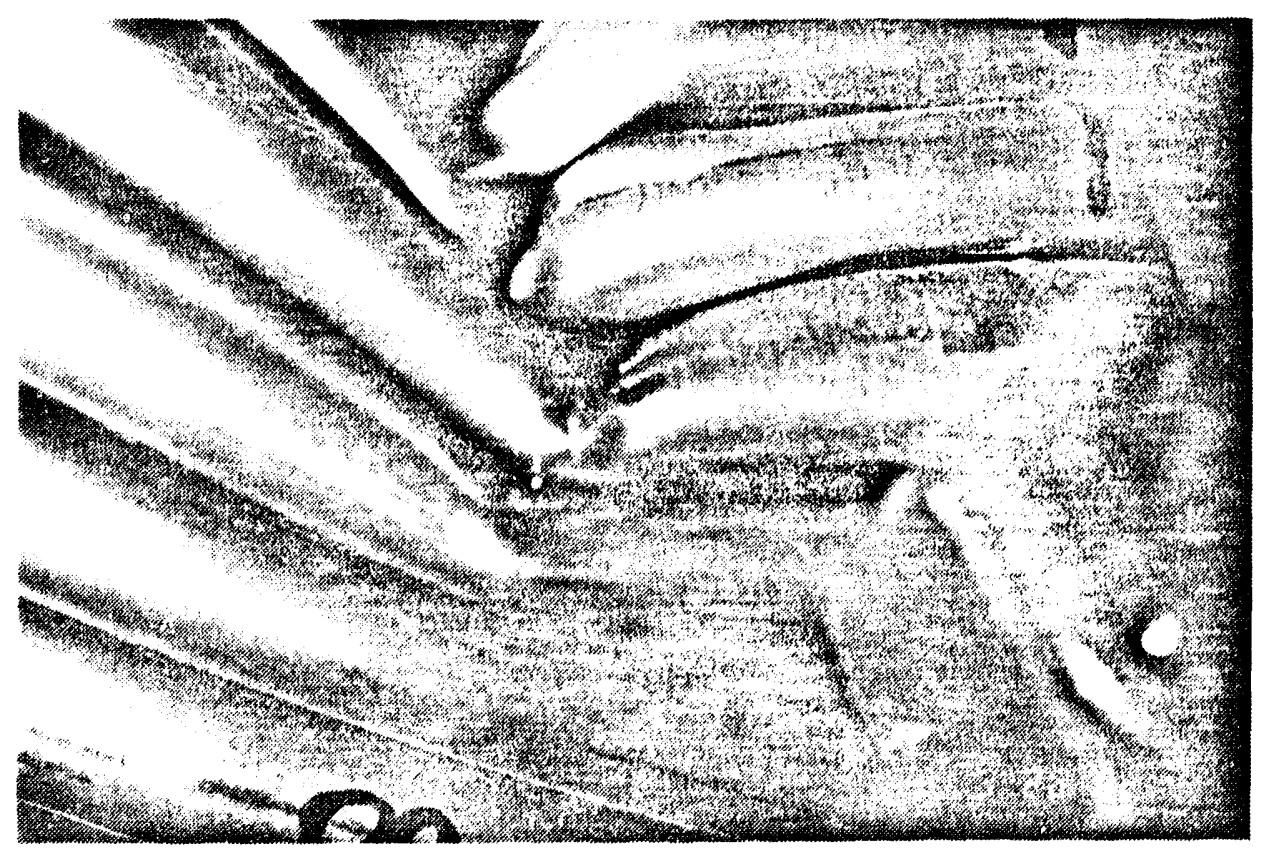

Figure 16. Bellows Specimen B-8-2-1

Tear at Sharp Crease

(Test I-3-SC)

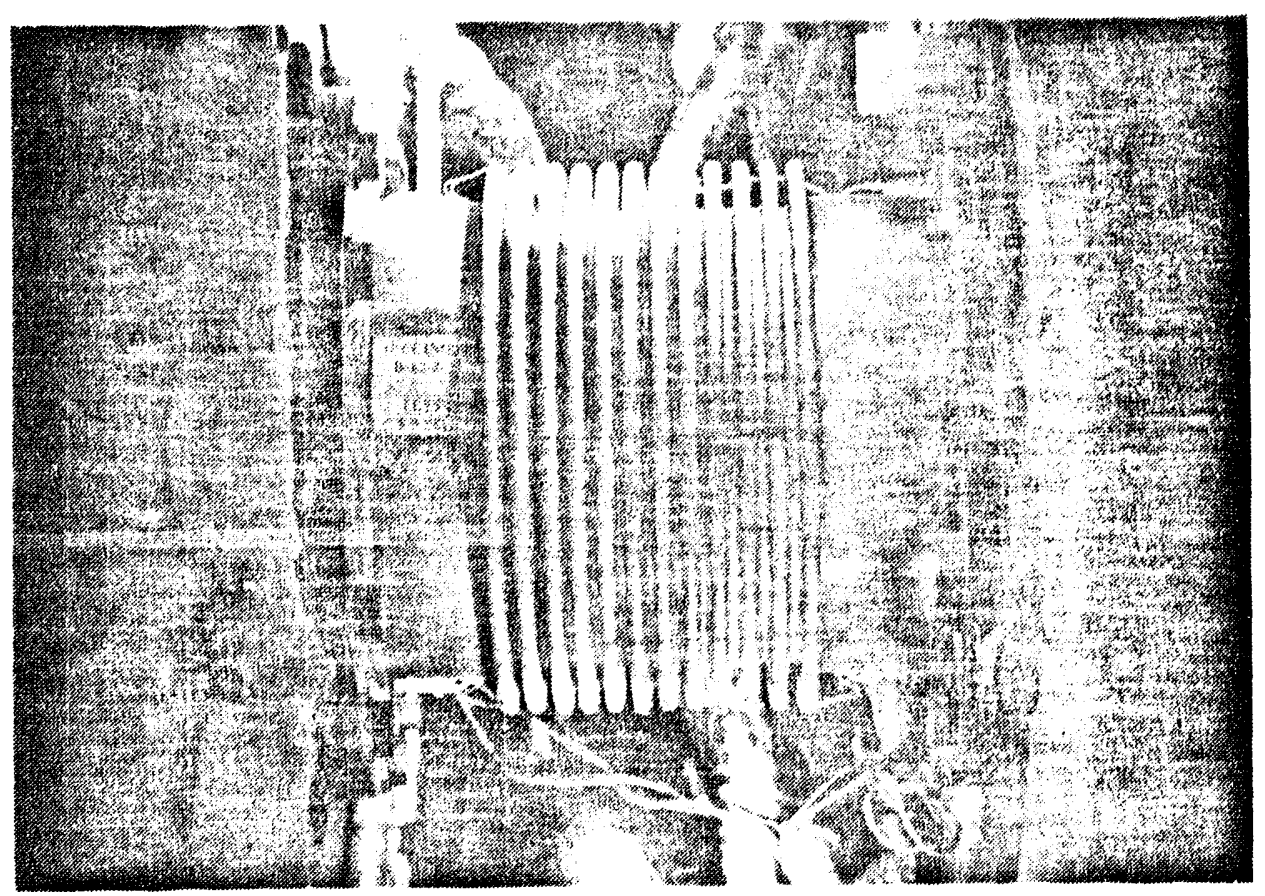

Figure 17. Bellows Specimen B-12-2-2

(Test I-9-SC) 
The axial and lateral displacements at the time of leakage for the elevated temperature test was 7-3/8 inches and 1-7/8 inches, respectively, (Figure 18) versus $8-3 / 8$ inches and 2 inches, respectively, for the room temperature test (Figure 19). Neither of the bellows reached the point of full axial compression before leakage began, but even the specimen tested at elevated temperature was over $35 \%$ compressed. For both specimens, full compression would have been reached at an axial displacement of approximately 8-1/2 inches. Internal pressure for the two tests were 72 psig for Test 19-SC and 68 psig for Test 1-10-SCT. In these tests the failure mode was different than most of the previous tests. Immiediately prior to leakage, the bellows convolutions were observed to roll over the end spool. The specimens have not been dissected to see exactly where the leak occurred, but it appeared to be a case of the spool cutting into the thin bellows material.

\section{Phase II Tests}

Two tests were completed on the larger piping penetration and vent-line bellows specimens. The vent line bellows specimen that was tested was a universal bellows of two ply construction. The test was $11-19-S C T$, utilizing specimen VL-2. Figure 20 shows the bellows at the start of the test. Insulation covers the end spools and lower part of the bellows to aid in maintaining the test temperature. The test was conducted at $425^{\circ} \mathrm{F}$, with a maximum internal pressure of $150 \mathrm{psig}$. The specimen proved to be very durable, and was subjected to two complete cycles of compression and extension without developing a leak. The lateral displacement was limited to 1 inch during the compression cycle because the specimen is approximately 1:4 scale, and that displacement is a conservative value for lateral shear that could be imposed by a containment building. After enduring two complete compression cycles, the bellows was sheared an additional amount laterally, while fully compressed at an internal pressure of $150 \mathrm{psig}$. The specimen developed a leak through the outside ply at a lateral displacement of approximately $2-1 / 2$ inches and leaked through both plies at approximately 2-7/8 inches lateral displacement (Figure 21).

The last test that was completed in this series was a full size piping penetration bellows identified as PP-2 (Figure 22). The sperimen was a universal bellows of twoply construction. The test identification number .as II-17-SCT. The test followed the parameters tabulated in Table 2, which represent a severe accident scenario for this type of bellows. The specimen was maintained at $425^{\circ} \mathrm{F}$ during the test, with a maximum internal pressure of 74 psig at full axial compression. The specimen developed a leak through the inner ply after being fully compressed. The outer ply did not develop a leak after two complete loading cycles. At this point, the bellows was displaced laterally an additional distance for a total lateral displacement of approximately 5 inches (Figure 23), which was the limit of the test apparatus. The direction of displacement was then reversed so that the bellows was being returned to lateral zero while maintaining full axial compression and maximum internal pressure. The outer ply began leaking as the lateral displacement approached 1-3/4 inches. 


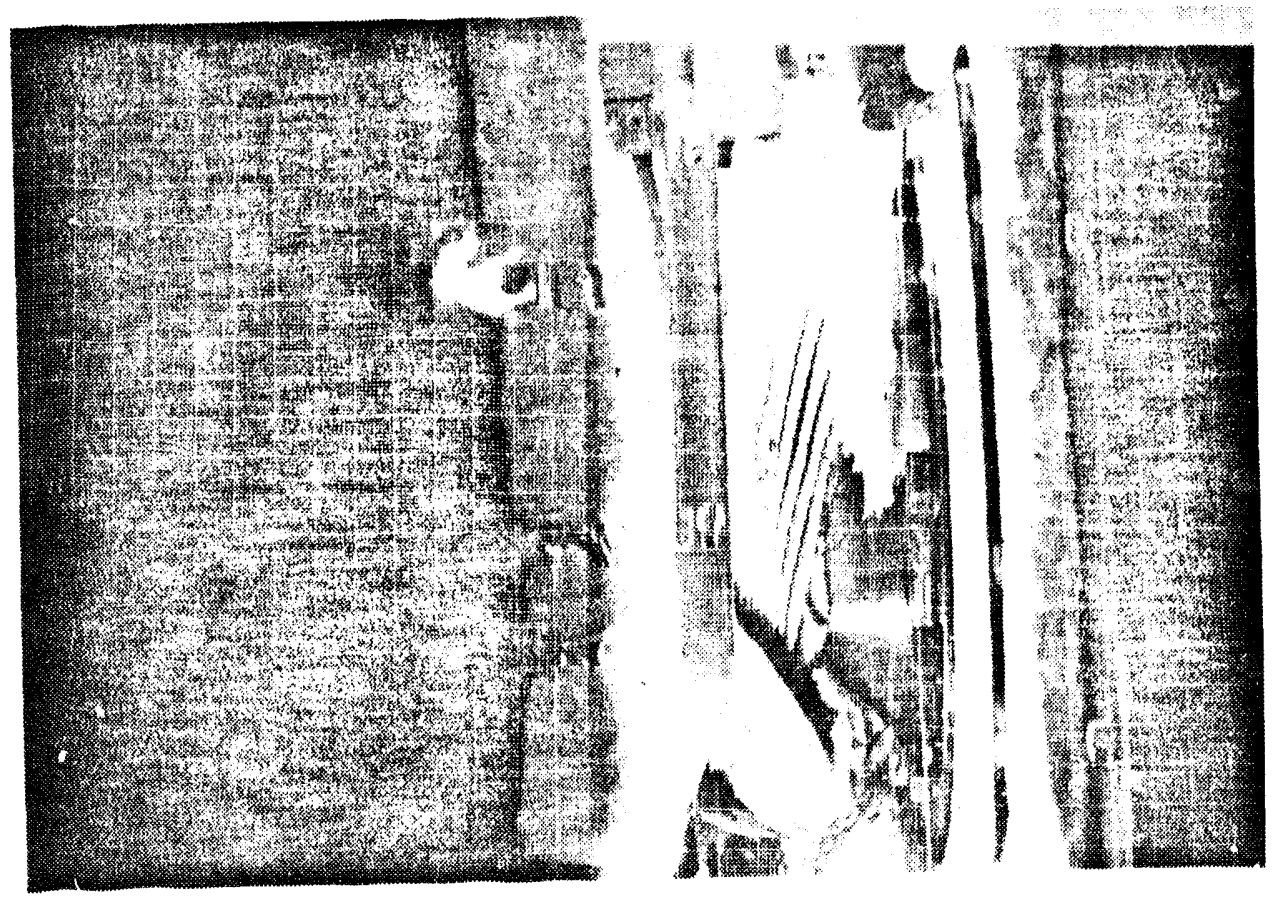

Figure 18. Bellows Specimen B-12-2-1

Begining of Leakage

(Test I-10-SCT)

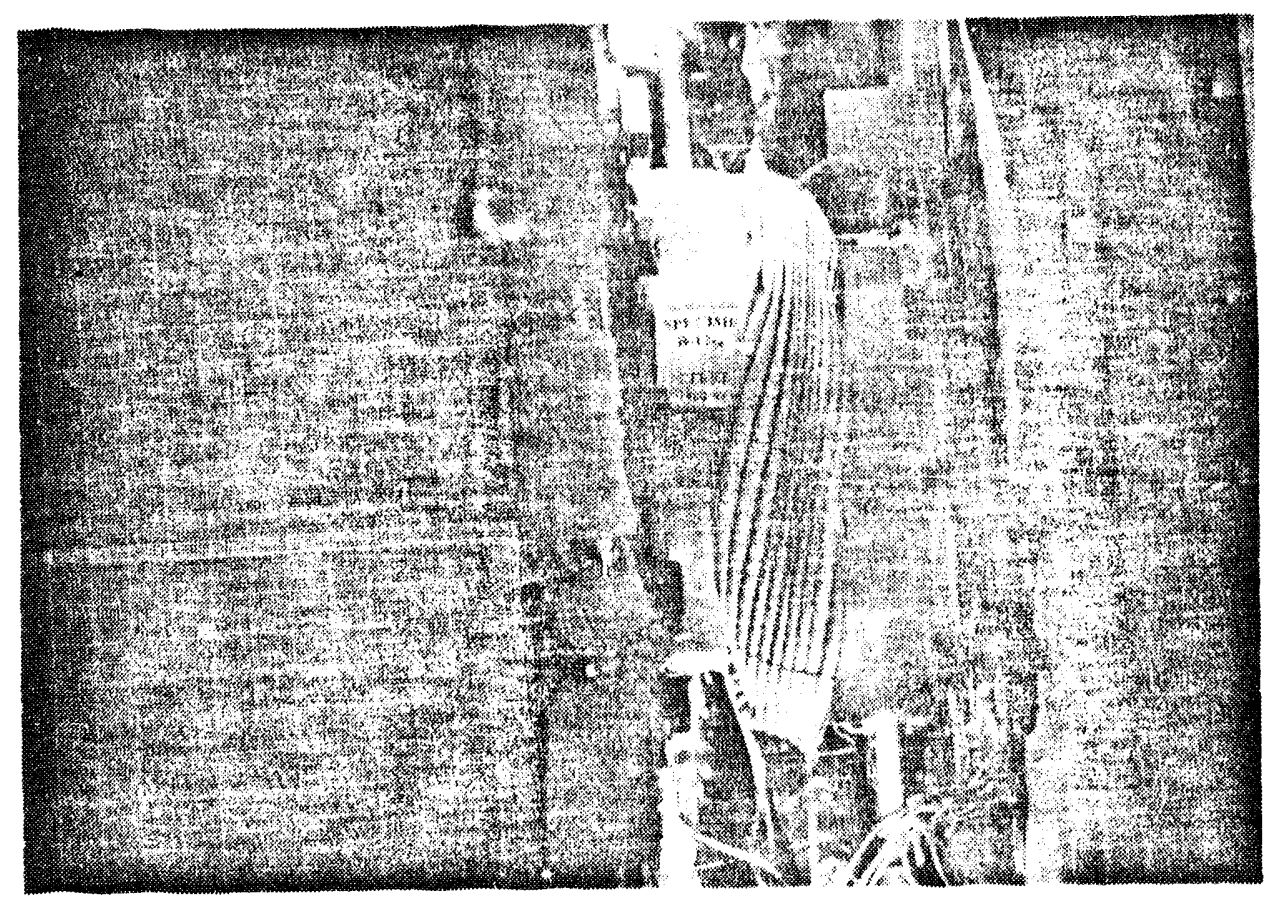

Figure 19. Bellows Specimen B-12-2-2

Begining of Leakage

(Test I-9-SC) 


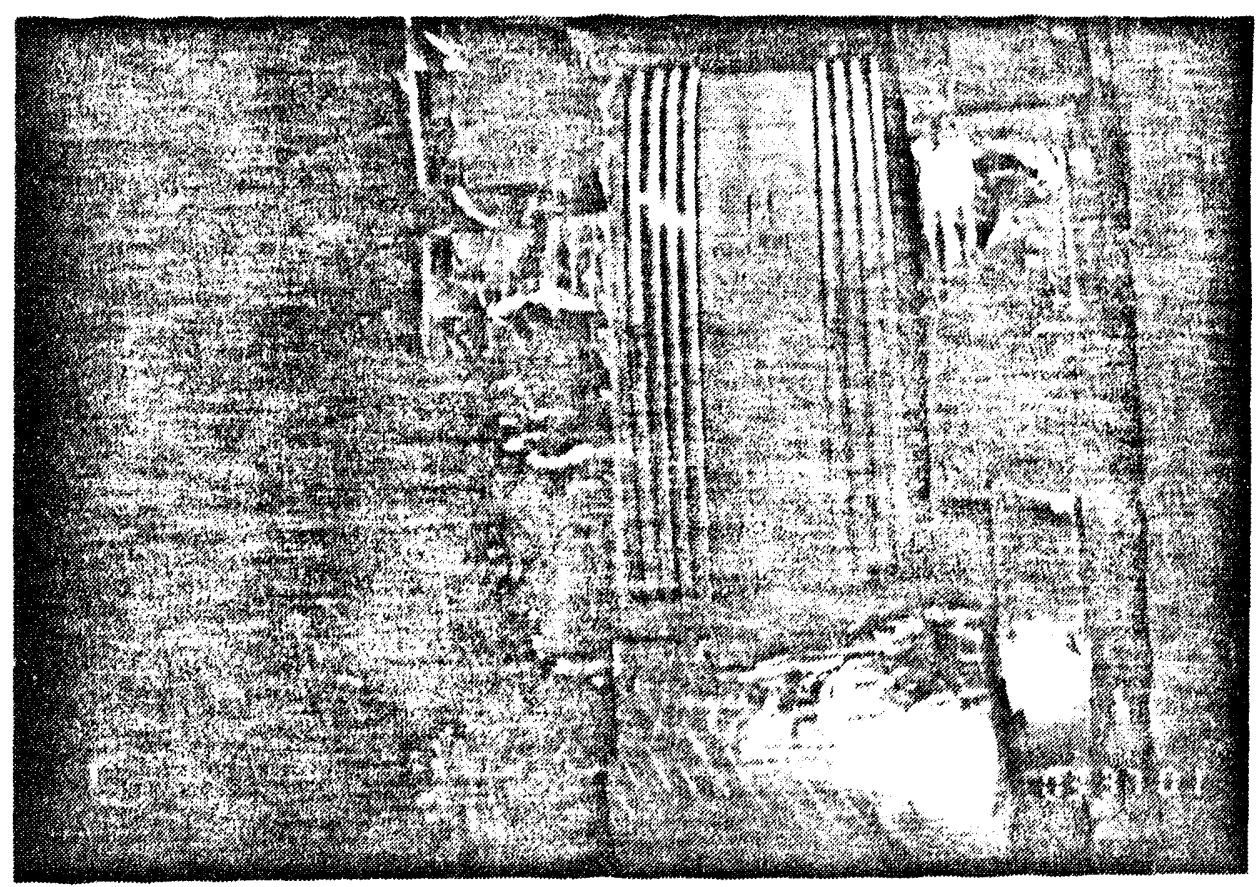

Figure 20. Bellows Specimen VL-2

(Test II-19-SCT)

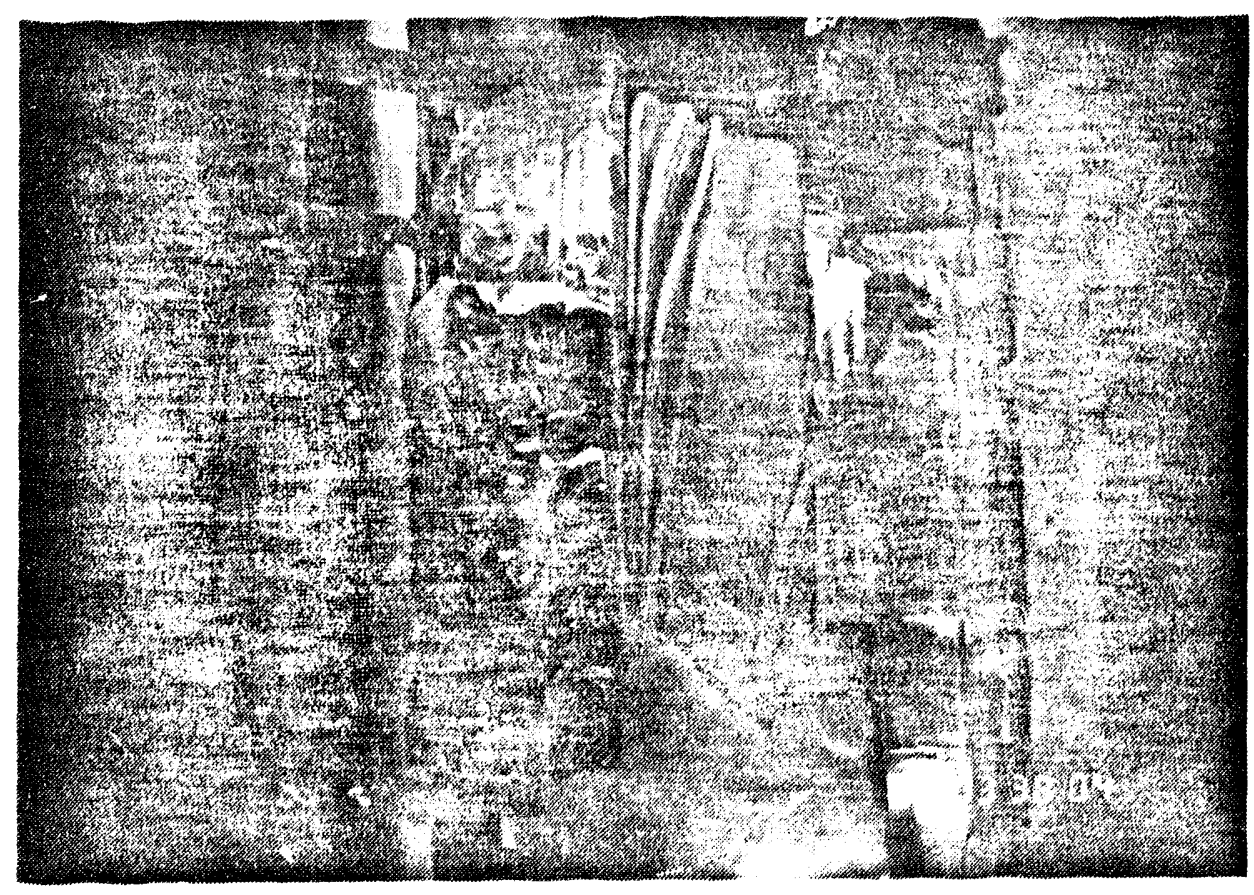

Figure 21. Bellows Specimen VL-2

Begining of Leakage

(Test II-19-SCT) 


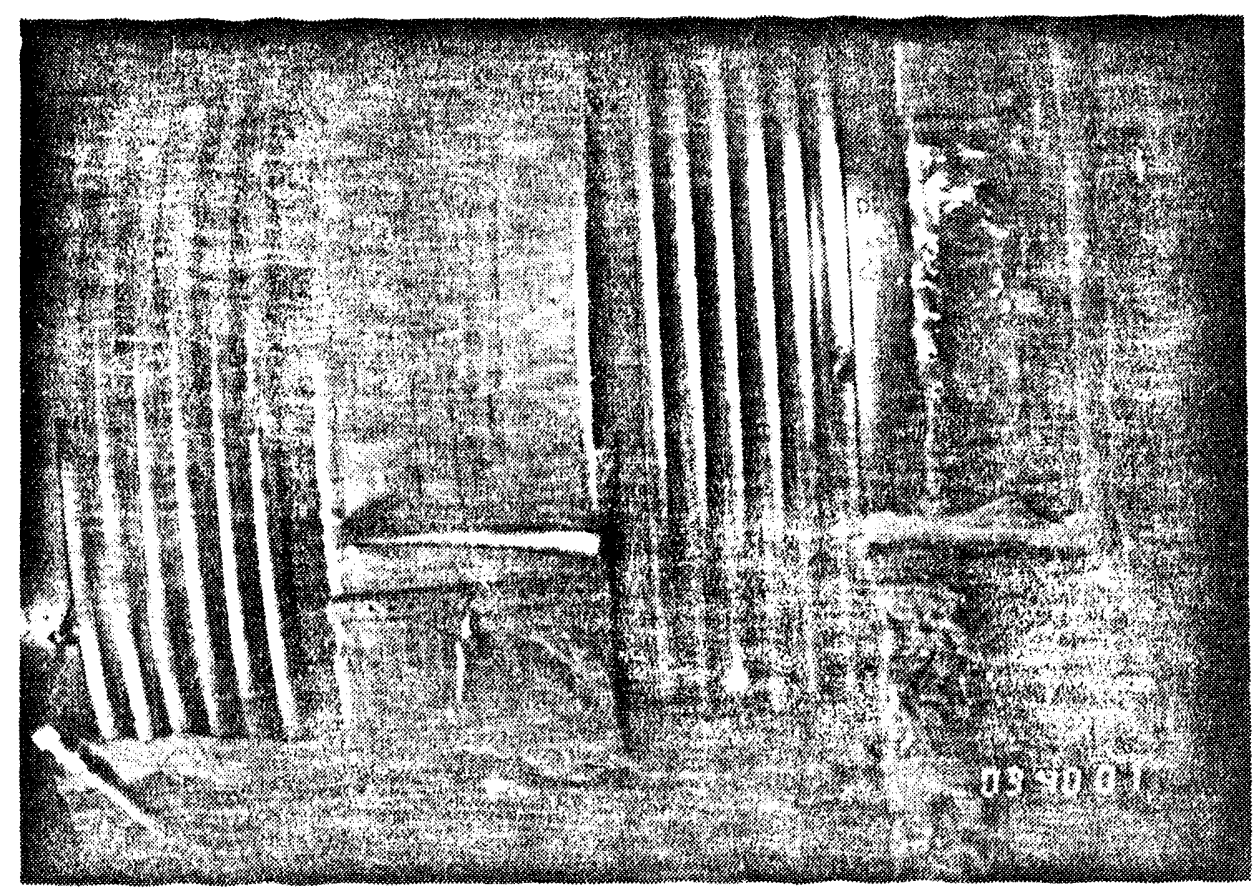

Figure 22. Bellows Specimen PP-2 (Test 11-17-SCT)

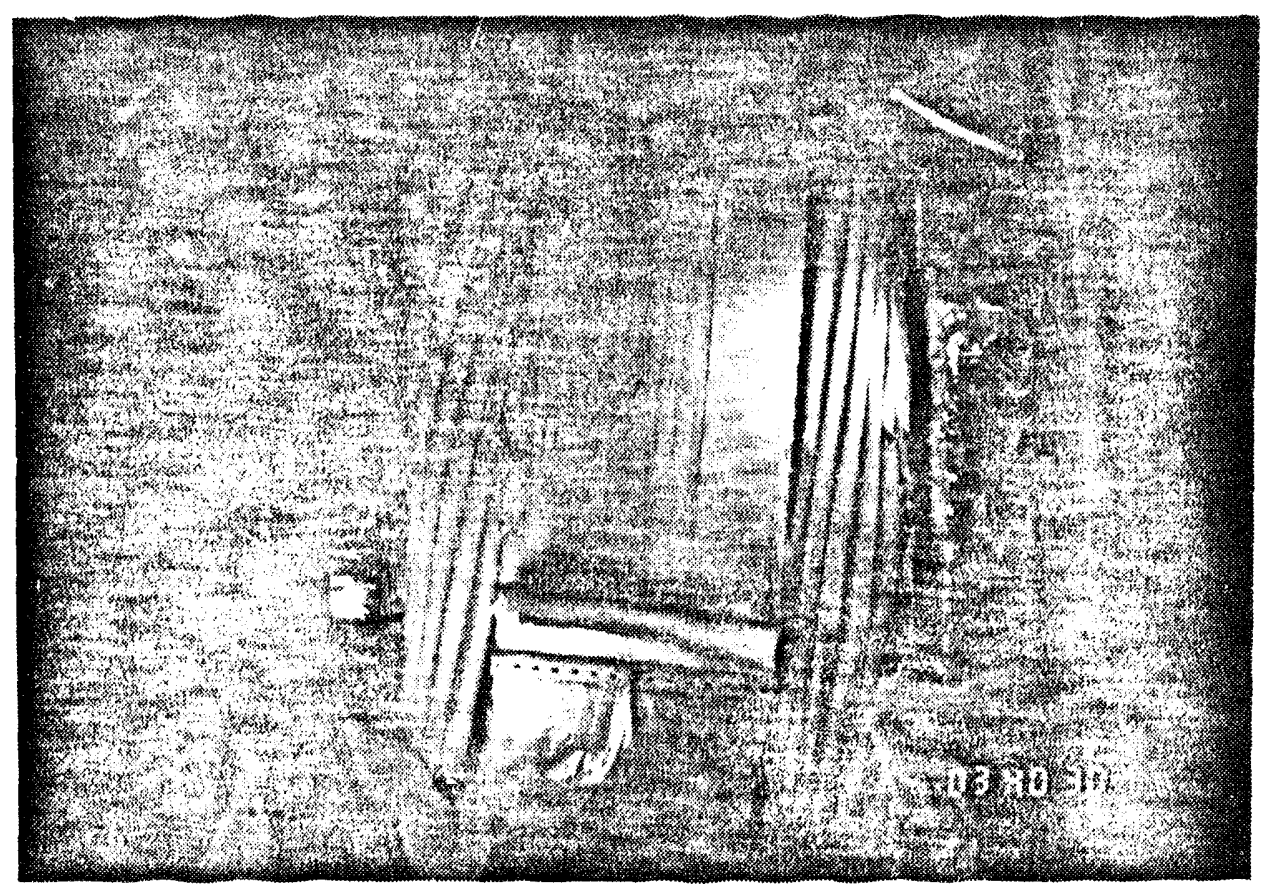

Figure 23. Bellows Specimen PP-2

Fully Compressed

(Test II-17-SCT) 


\section{DISCUSSION}

The tests that have been conducted thus far indicate that bellows are capable of enduring extreme loads in the form of relatively large displacements, and elevated internal pressure and temperature while remaining leak tight. Bellows capacity is somewhat degraded by temperature, but they still are capable of remaining leak-tight during extreme conditions.

As expected, the universal type of bellows can withstand more extreme lateral displacements due to its design. Sharp creases do not develop until the lateral displacement is very large. Another geometric factor that affects performance is the depth of convolutions. The deeper convolutions develop sharp creases with less lateral displacement than those with shallow convolutions. Tears usually developed at one of these creases. The deeper convolutions also seem more prone to roll over the end spools and possibly be sheared by them.

These tests show that a wide range of containment bellows, if in 'good' condition, will remain leak-tight up to, or near, the point of full axial compression, while subjected to extreme conditions of internal pressure, elevated temperature, and lateral deformation. After being fully compressed, additional outward movement of the containment will likely cause large leakage as the bellows are either cut by the end spools or the connection of the bellows to the end spools will fail, since it was not designed to withstand this type of loading.

Since all the bellows in this series were tested in 'like-new' condition, the question of degraded capacity as a result of corrosion has not been answered. The specimens that were not tested during this series of tests will be subjected to accelerated corrosion and iested at a later date.

\section{REFERENCES}

[1] M. B. Parks, D. S. Horschel, W. A. vonRiesemann, Summary of NRC-Sponsored Research on Containment Integrity, Transactions of the Eleventh Conference on Structural Mechanics in Reactor Technology, Tokyo, Japan, 1991.

[2] L. Greimann, et al., Analysis of Bellows Expansion Joints in the Sequoyah Containment, NUREG/CR-5561, SAND90-7020, Sandia National Laboratories, Albuquerque, New Mexico (December 1991).

[3] M. H. Shackleford, et al., Characterization of Nuclear Reactor Containment Penetrations, NUREG/CR-3855, SAND84-7180, Sandia National Laboratories, Albuquerque, New Mexico (1985)

[4] Standards of the Expansion Joint Manufactures Association. Inc., 5th Edition, (1985 addenda), EJMA, Inc., 25 North Broadway, Tarrytown, NY. 

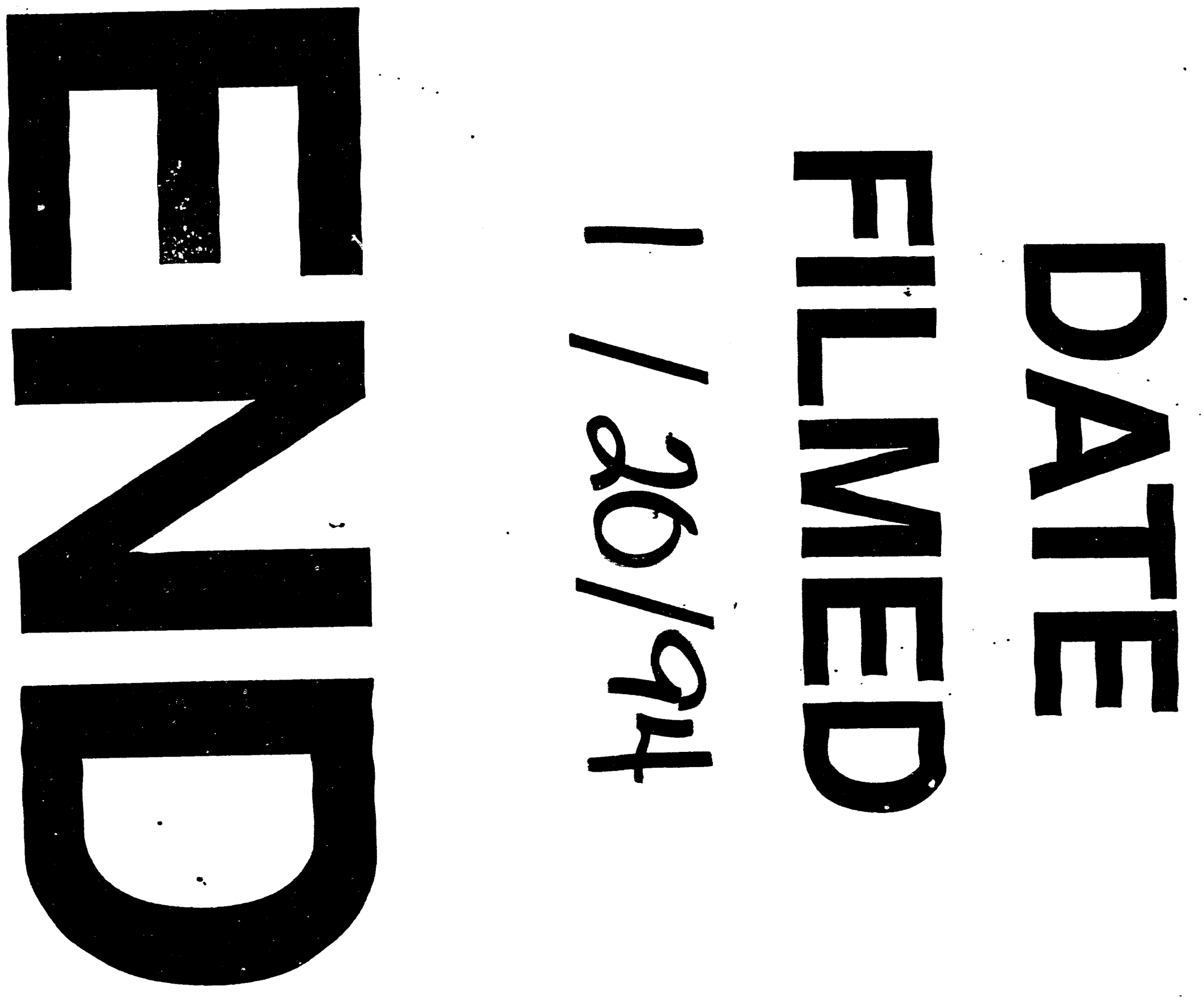


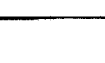

$-$

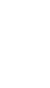

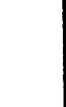

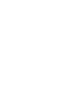

. 